\title{
Public Health Investments and the Infant Mortality Gap: Evidence from Federal Sanitation Interventions on U.S. Indian Reservations
}

\author{
Tara Watson* \\ This draft: August 2005
}

\begin{abstract}
To what extent do differential levels of investment in public health inputs explain observed differences in health outcomes across socioeconomic and racial groups? This study investigates the impact of 3,700 projects that were part of a widespread Federal initiative to improve sanitation infrastructure on U.S. Indian reservations starting in 1960. Sanitation investment substantially reduced the cost of clean water for households, leading to sharp reductions in both waterborne gastrointestinal disease and infectious respiratory disease among Native American infants. The sanitation program was quite cost-effective, in part because improvements in the overall disease environment also reduced infectious respiratory disease among nearby white infants. Despite the health externalities, Federal sanitation interventions explain almost forty percent of the convergence in Native American and white infant mortality rates in reservation counties since 1970 .
\end{abstract}

*Williams College. I would like to thank Doug Almond, Ken Chay, David Cutler, Claudia Goldin, Nora Gordon, Caroline Hoxby, Sandy Jencks, James Ludington, Ofer Malamud, Cristian Pop-Eleches, Sarah Reber, Albert Saiz, Werner Troesken, Abigail Waggoner, participants in seminars at several universities and the NBER Summer Institute, several anonymous referees and especially Larry Katz for many helpful comments. The Department of Environmental Health and Engineering of the Indian Health Service and the National Center for Health Statistics graciously accommodated numerous data requests. The Indian Health Service staff at the Blackfeet and Ft. Belknap Reservations in Montana and at Headquarters in Maryland also took the time to meet with me. I am indebted to the Social Science Research Council Program in Applied Economics and the Harvard University Multidisciplinary Program in Inequality and Social Policy for research support. Beke Ncube provided excellent research assistance. All remaining errors are my own. Please send comments to twatson@williams.edu. 


\title{
Public Health Investments and the Infant Mortality Gap: Evidence from Federal Sanitation Interventions on U.S. Indian Reservations
}

\begin{abstract}
To what extent do differential levels of investment in public health inputs explain observed differences in health outcomes across socioeconomic and racial groups? This study investigates the impact of 3,700 projects that were part of a widespread Federal initiative to improve sanitation infrastructure on U.S. Indian reservations starting in 1960. Sanitation investment substantially reduced the cost of clean water for households, leading to sharp reductions in both waterborne gastrointestinal disease and infectious respiratory disease among Native American infants. The sanitation program was quite cost-effective, in part because improvements in the overall disease environment also reduced infectious respiratory disease among nearby white infants. Despite the health externalities, Federal sanitation interventions explain almost forty percent of the convergence in Native American and white infant mortality rates in reservation counties since 1970 .
\end{abstract}


Substantial disparities in health outcomes exist across racial and socioeconomic groups. On average, economically advantaged groups are healthier and populations become healthier as their economies develop. ${ }^{1} \quad$ Less clear is the extent to which differential levels of investment in various public and private health inputs explain the observed differences in health. This study exploits a series of water and sewer projects implemented by the Federal government on U.S. Indian reservations starting in 1960. The results show that sanitation investment led to a sizable and cost-effective reduction in the infant mortality rate of the targeted beneficiaries, Native Americans, and an additional, although much smaller, reduction in mortality of nearby white infants. ${ }^{2}$

Between 1960 and 1998, the infant mortality of Native American infants in reservation counties fell from 53 to 9 per 1000, while white infant mortality declined from 26 to 6 per 1000 (see Figure 1). Thus, there was a substantial reduction in the Indian-white infant mortality gap in reservation counties and in the country overall. ${ }^{3}$ The convergence was particularly dramatic for post-neonatal deaths and for deaths from gastrointestinal diseases. ${ }^{4}$ Several recent papers have explored the determinants of the black-white infant mortality gap, but virtually no work has investigated the impressive reductions in infant mortality among American Indians. ${ }^{5}$

\footnotetext{
${ }^{1}$ A person born in a high-income country can expect to live 19 years longer than a person born in a lowincome country on average (World Bank, 2002, based on 2001 data. Low income countries are the 66 countries in income range $<\$ 745$ GNI per capita and high income countries are the 52 countries in income range $>\$ 9206$ GNI per capita.) Similarly, disadvantaged groups within countries have inferior health outcomes. In the United States, the white and nonwhite infant mortality rates are 5.7 and 11.4 per 1000, respectively. (National Center for Health Statistics, 2002, Table 34 based on 2000 data.)

${ }^{2}$ In this paper, I use the terms Native American and Indian interchangeably to describe American Indians and Alaskan Natives.

${ }^{3}$ The fraction of Indian births in urban areas grew from 28 percent to 46 percent, in part due to changing ethnic identification among the population. The infant mortality rate for urban Indians was 21 per 1000 in 1960, lower than the white urban rate of 27 per 1000. In 1998, the Indian and white urban rates were 9 and 6 per 1000 , respectively, and similar to the rates in reservation counties.

${ }^{4}$ Post-neonatal deaths fell from 29.5 to 4.7 per thousand and gastrointestinal deaths fell from 7.4 to 0.2 per thousand over the period for Indians in the sample. Among whites in the same county groups, gastrointestinal mortality rates were quite low throughout the period, but fell from 0.5 to 0.1 per thousand.

${ }^{5}$ The nonwhite-white gap in infant mortality narrowed substantially in the 1925-1945 period (Collins and Thomasson, 2002). The bulk of the change appears to have been driven by relative improvements in postneonatal mortality ( 28 days to 11 months), typically affected by environmental factors such as infectious disease. Since 1965, nonwhite post-neonatal and neonatal mortality have both moved closer to white levels. Chay and Greenstone (2000) and Almond, Chay and Greenstone (2003) argue that Civil Rights-era desegregation of hospitals played a part in this convergence.
} 
In the 1950s, the American public grew increasingly aware of substandard living conditions on Indian reservations. A 1952 U.S. government report documented that most Indians living on reservations hauled water for household use and drank water from potentially contaminated sources (Department of Health and Human Services, 1999). The 1955 Indian infant mortality rate on reservations was estimated at 63 per 1000, comparable to 1960 rates in Venezuela and Jamaica. ${ }^{6}$ These findings, coupled with an administrative change regarding Indian health care at the federal level, prompted Congress to adopt the Sanitation Facilities Construction Act. The 1959 legislation authorized sanitation improvements in Indian country under the auspices of what is now the Indian Health Service. Since 1960, the Sanitation Facilities Construction program has averaged about 33,000 homes served and $\$ 80$ million spent (in 2000 dollars) annually.

Sanitation infrastructure is one of a wide range of health inputs on Indian reservations provided by the Federal government in recent decades. ${ }^{7}$ The impacts of these sizable public outlays on the health of Native Americans and neighboring whites have not been previously studied. $^{8}$ This paper focuses on 3,700 Federal sanitation interventions implemented as part of the Indian Health Service Sanitation Facilities Construction Program between 1960 and 1998.

How much do improvements in sanitation affect health outcomes? Several recent papers have found sizable effects. Cutler and Miller (2005) find large reductions in urban mortality in the U.S. following water filtration and chlorination in the early twentieth century. Galiani et al. (2005) find an 8 percent reduction in child mortality in parts of Argentina that privatized sanitation in the 1990s. Troesken (2001) finds beneficial

\footnotetext{
${ }^{6}$ Venezuela and Jamaica had infant mortality rates of and 56 and 58 per 1000 in 1960, respectively (UNICEF, 2002).

${ }^{7}$ In addition to sanitation and hospital care, other services include dental care facilities, health clinics, and substance abuse facilities. The Indian Health Service budget in 2001 was around 2.6 billion dollars, or almost $\$ 2000$ per Indian eligible for services. The Federal government is heavily involved in many aspects of reservation life. A GAO Report found sixteen Federal programs targeted exclusively to Indian economic development, for example (General Accounting Office, 2001).

${ }^{8}$ Despite the lack of systematic evidence on this point, the Indian Health Service largely takes credit for the gains in Indian health (Rhoades et al., 1987 and Rhoades et al., 1992). Relatively few papers in the economics literature have explored Native American issues. Notable exceptions include work on casinos by Evans and Topoleski (2002), on wages by Gitter and Reagan (2002), and on political economy by Cornell and Kalt (1995). Data limitations are an important reason that the group has not been extensively studied; sample sizes of Native Americans in most surveys are too small to perform meaningful analysis.
} 
effects of municipalization on typhoid rates among blacks in early twentieth century America. More generally, however, the literature is mixed. A review of 17 studies examining the effect of various sanitation interventions finds ten with positive results and seven without (Esrey et al., 1990). ${ }^{9}$ In general, most studies of large-scale sanitation improvements rely on non-random assignment to the treatment because the decision to invest in sanitation is correlated with economic growth and other factors. It is therefore difficult to differentiate the causal effect of sanitation from a variety of other changes occurring around the same time that could potentially affect health outcomes.

The Sanitation Facilities Construction (SFC) program offers a particularly good opportunity to identify the causal impact of sanitation improvements. The program rules require that sanitation projects are allocated according to a formula based primarily on need, and the total budget is subject to the overall whims of Congressional funding. The exact timing of projects on a given reservation is therefore unlikely to be correlated with other factors that could independently affect infant health. The 3,700 projects in the sample vary widely in size, location, and implementation date. The fact that the interventions are relatively recent also allows one to take advantage of modern microdata on vital statistics in the United States. ${ }^{10}$

The empirical analysis shows that sanitation interventions have large effects. A 10 percentage point increase in the fraction of homes receiving sanitation improvement reduced Indian infant mortality by 0.51 per 1000 births, or by 2.5 percent. Reductions in infant mortality were concentrated in waterborne gastrointestinal diseases and infectious respiratory diseases. The Indian infant mortality rate would be about 50 percent higher today in sample areas in the absence of the program. Sanitation investments also appear to have been fairly cost effective. The estimated $\$ 217,000$ cost of saving a Native American infant is well below other interventions targeted at improving infant health.

\footnotetext{
${ }^{9}$ The paper reviews studies of various kinds; here I focus on those that considered diarrhea morbidity or mortality as an outcome.

${ }^{10}$ The ability to use population data is important in the study of Indian outcomes because group samples in most surveys are too small to perform meaningful analysis.
} 
Smaller but significant benefits of the Sanitation Facilities Construction program accrue to white infants. These benefits mainly arise from an improved disease environment rather than as a direct result of improved water quality. Despite the spillovers to nearby white infants, the interventions substantially reduced the Indian-white infant mortality gap. In reservation counties, which experienced many changes over recent decades, the sanitation program explains 40 percent of the convergence since 1970.

The evidence presented here complements a growing literature that evaluates the effect of public health interventions on a variety of outcomes. Bleakley (2002) documents the positive impact of the eradication of hookworm in the American South on schooling and income. Miguel and Kremer (2004) find an effect of deworming medication on school attendance in Kenya. Recent research has also shown that clean air legislation in the 1970s reduced infant mortality (Chay and Greenstone, 2003) and that bans on lead in gasoline reduced crime a generation later (Reyes, 2002). Investments in public health appear to have beneficial effects on economic outcomes, presumably mediated by their impacts on health.

The paper proceeds as follows. Section 1 contains an overview of Native American sanitation and the SFC program. Section 2 presents a simple conceptual framework. Section 3 explains the data and the empirical strategy. Section 4 describes the evidence on the overall effect of sanitation on Indian infant mortality and considers the role of health externalities on whites. The implications of the estimates are explored in Section 5, and Section 6 concludes.

\section{Native American Health and Federal Health Interventions}

Native Americans are among the most economically disadvantaged groups in American society. As of the 2000 Census, 29 percent of adults lacked a high school degree, and only 12 percent had a bachelor's degree. ${ }^{11}$ Unemployment rates are high, and on reservations often exceed 50 percent. Poverty rates of 26 percent make Native

\footnotetext{
${ }^{11}$ Author's analysis of 2000 data from Integrated Public Use Microdata System (IPUMS). Analysis includes those over 25 who selected American Indian as their only race. In comparison, 14 percent of blacks and 26 percent of whites had a bachelor's degree.
} 
Americans as poor as any major racial group. ${ }^{12}$ Other social indicators also reflect hardship: Native Americans are more likely than any other group to be the victim of violent crime, ${ }^{13}$ and the age-adjusted mortality rate is 39 percent higher than that of the population at large. ${ }^{14}$

By treaty obligation in some cases and historical precedent in others, the Federal government has assumed long-standing responsibility for Indian health care. Until 1955, the health care burden fell on Bureau of Indian Affairs (BIA, part of the Department of War until 1949), which failed to achieve an acceptable level of health among the Indian population during its tenure. A 1952 survey of Native American households on selected reservations reported that more than 80 percent carried water for household use, and most drank water from potentially contaminated sources (Department of Health and Human Services, 1999). In 1955, when responsibility for Indian health care was transferred to the Department of Health, Education and Welfare, infectious diseases such as dysentery and influenza were endemic. More than five percent of Native American children died in the first year of life.

Along with the transfer of Federal responsibility for Indian health care came a new commitment to Indian health. Hospital facilities were deemed inadequate, and Congress appropriated funds to upgrade existing facilities starting in 1956. Federal appropriations allowed for twelve major hospital projects in the 1960s, half of which represented new construction. Most of the new hospitals had less than 50 beds and were located in isolated, previously underserved communities.

The Federal government also sought to improve sanitation in an effort to raise health levels and quality of life. In 1960, 28 percent of all rural Native American households lacked access to a water system or well, compared to 4 percent of rural white households. More than half of rural Native American households lacked access to a sewer system or septic tank. Around the same time, the so-called "Kentucky study" published by the Public Health Service showed a cross-sectional correlation between sanitation facilities

\footnotetext{
${ }^{12}$ U.S. Census Bureau (2001a), based on 1998-2000 data.

${ }^{13}$ U.S. Census Bureau (2001b), Table 307.

${ }^{14}$ Department of Health and Human Services (2002) based on 1998-1999 data, p. 53.
} 
and gastrointestinal illness. ${ }^{15}$ In 1959, Congress authorized the Sanitation Facilities Construction (SFC) Act to enable the provision of water and sewer systems for Indian homes on and near reservations. Largely as a result of this program, sanitation levels improved substantially over time, both absolutely and relative to white households. ${ }^{16}$

Table 1a summarizes the characteristics of the sanitation projects examined in the analysis. A typical project serves 100 homes. and takes two years from the appropriation year to the completion year. The range of activities funded includes digging wells, providing latrines or septic tanks, building or improving water or sewer treatment plants, extending water and sewer lines, and connecting individual homes to those lines.

How are projects allocated across reservations? The answer to this question is important to the validity of the empirical strategy. The Indian Health Service (IHS) maintains a database of Native American households on or near Indian reservations. It rates these homes for sanitation deficiency based on the adequacy of its sewer and water systems. Twelve administrative sub-units (called Areas) organize subsets of the deficient homes into projects. To initiate the project a tribe must formally make a request for assistance. Despite the formal involvement of the tribe, both the allocation of resources across reservations and the timing of projects are determined largely by factors outside of tribal control. Project funding is prioritized among projects based on a formula that emphasizes "unmet needs," in other words the fraction of homes served by the project with various levels of sanitation deficiencies. ${ }^{17}$ The total SFC Program funding is determined by the Congressional budget process and varies from year to year. The allocated funds are distributed across Areas, which then fund projects according to the priority list (Department of Health and Human Services, 1999). ${ }^{18}$ The resulting distribution of projects across areas is described in Section 3.

\footnotetext{
${ }^{15}$ U.S. Department of Health, Education and Welfare (1958).

16 An analysis of IPUMS census microdata for states included in the analysis suggests that the fraction of Indian households with complete plumbing increased from 36 percent in 1960 to 96 percent in 2000.

${ }^{17}$ Prioritized projects must be declared to be "feasible," which means their costs do not substantially exceed those of comparable projects in the Area.

${ }^{18} \mathrm{I}$ do not have data on the priority ranking of individual projects so a regression discontinuity design is not feasible.
} 
In the empirical analysis, I include data on the number of Indian Health Service hospitals in an area. The mechanism underlying appropriations for Indian Health Service hospital construction is less formal and possibly subject to manipulation by tribes. Furthermore, hospital construction is likely to be correlated with the recording of births and infant deaths. I treat the number of hospitals a control variable rather than a main variable of interest.

\section{Conceptual Framework}

Why does sanitation matter? Sanitation improvements can be viewed as reductions in the cost of obtaining clean water. ${ }^{19}$ Households without access to a water system typically must carry water from a central cistern or natural water source. Water is quite costly in terms of time and effort. The 1952 survey of Native American households on reservations found water usage of one gallon per person per day to be common, compared with an average of 50 to 60 gallons in urban areas at the time. A substantial reduction in the cost of obtaining water would likely increase the quantity consumed for hand-washing, bathing, and overall household cleanliness. This behavioral response to sanitation investment likely would be observed in the incidence of diseases spread by person-to-person contact such as respiratory disease. ${ }^{20}$ In principle, the reduction in respiratory disease would be observed among households receiving the sanitation improvement as well as other members of the community with whom they would be in contact. The effect should be greatest in densely populated areas.

In addition to inducing a behavioral shift, sanitation investment may directly impact health by improving water quality. Water may be contaminated by chemical toxins or infectious organisms, particularly in the absence of a sewer system. Inadequate sewerage is associated with the transmission of a number of infectious gastrointestinal diseases through the fecal-oral pathway. Young children are particularly susceptible to many of

\footnotetext{
${ }^{19}$ An excellent resource on the subject is "Water and Sanitation," published on behalf of the World Health Organization (2001). Although the impact of water and sewer investments are somewhat distinct, they are highly complimentary, and are most appropriately considered components of one unified sanitation system. In my empirical work I cannot distinguish water and sewer projects.

${ }^{20}$ Chin (2000) notes that personal hygine and the avoidance of hand to mucous membrane transmission is an important preventative measure for influenza, for example. Pneumonia is spread through droplets.
} 
these illnesses (Chin, 2000). Gastrointestinal disease can be fatal or can lower a child's resistance to other potentially fatal diseases like pneumonia. A household's investment in sewerage reduces the level of infectious disease in the community sanitation network. This will tend to benefit other households with inadequate sanitation facilities. In other words, untreated water is safer to drink if those potentially contaminating it are healthier. This effect is predicted to be most important in communities with low levels of sanitation and to be reflected in rates of spread through fecal-oral transmission such as gastrointestinal disease.

Thus, an investment by the household in water or sewerage improves the health of its members, which in turn generates a health externality benefiting its neighbors. In the absence of a either a Coasian market in which these externalities are traded or a wellfunctioning government, the level of investment in water and sewerage will be inefficiently low. This issue is compounded by the large fixed cost associated with some types of sanitation projects (such as upgrading a water filtration plant) and capital market imperfections. Both the health externality and the potential free-rider problem point to the social benefit of public provision of sanitation

The question of which public entity should have provided health facilities on Indian reservations is a complicated one. Theoretically, tribes could have invested in sanitation projects if they believed them to have large returns and were not credit-constrained. The lending market on Indian reservations has historically been very weak, however. ${ }^{21}$ The degree to which tribal members believed in the benefits of modern medicine varied. Furthermore, after a long history of subjugation by the Bureau of Indian Affairs, many tribal governments were in disarray by the mid-1950s. This combination of factors makes it unsurprising that it is the Federal government that has been the major provider of health facilities on Indian reservations. Federal provision may be advantageous if externalities are important. The issue is revisited in Section 6.

\footnotetext{
${ }^{21}$ Kolluri and Rengert (2000) report that private mortgage lending on Indian reservations is extremely rare. As of 1994, homeowners in the Navajo Nation had no private mortgage loans. Impediments to lending include the fact that the private sector is reluctant to contract over areas where state and local courts lack jurisdiction. The Federal government holds land in trust which cannot be sold by tribes or individuals. The GAO (2001) notes that "access to capital is difficult for tribes, sometimes because they have insufficient collateral" (p.13).
} 


\section{Data and Empirical Strategy}

\subsection{Data}

The SFC program data are graciously provided by the Department of Environmental Health and Engineering of the Indian Health Service (IHS). The database lists all projects funded by the program, and includes information on the number of homes served, the appropriation date, the completion date, and the IHS Area. In some cases, information on the reservation and/or tribe is also included. In cases of missing information on the name of the reservation, the project name and the IHS Area are used to determine the location of the project. Reservations are identified in about 85 percent of the cases, and projects with an ambiguous location are discarded from the sample. I exclude the small fraction of projects which last more than five years because their effects are likely to occur incrementally and are therefore difficult to identify. Other unusual projects and projects in Alaska are excluded as well. ${ }^{22}$

The mortality data comes from the Mortality Detail Files published by the National Center for Health Statistics (NCHS). I use publicly available data for the years 19681998. ${ }^{23}$ Unpublished NCHS mortality detail data is used for years prior to 1968. Natality data for the years 1968-1998 also comes from publicly available NCHS files. The natality and mortality detail files contain either a 50 or 100 percent sample of all United States deaths in each year. For years prior to 1968 , data on the number of live births by county by race is collected from state vital statistic offices or imputed.

Several limitations of the data are discussed in the data appendix. One important issue is that the SFC Program data provides information at the reservation level, while Vital Statistics data provides data on the county of residence. Reservations frequently cross county boundaries, and some counties contain more than one reservation. To deal with

\footnotetext{
22 The data appendix describes the selection criteria for projects.

${ }^{23}$ Permission was obtained to access confidential county identifiers for data years starting in 1989 for natality and mortality data.
} 
this issue, I aggregate counties into "county groups" so that every relevant county and every reservation is in exactly one county group. ${ }^{24}$

Hospital data is from the American Hospital Association electronic files which include a list of all hospitals in operation biannually from 1970 to 1984 and annually from 1986 to 2000. The hospitals are matched to counties using AHA published books for 1966 and 1968. For odd years 1967-1985, I assume a hospital is in operation if it is in operation the subsequent year. For years prior to 1966, I incorporate information from an Indian Health Service report on hospital construction (U.S. Public Health Service, 2000). There are 29 IHS hospitals in the analysis at the beginning of the period and 36 hospitals at the end of the period.

The county group-year is the unit of analysis in the empirical work. I exclude county groups with fewer than 50 Indian live births in any sample year and one county group that received no sanitation projects during the sample years. The final analysis examines 3,700 sanitation projects, 37 hospitals, and 38 county groups observed in 39 years. $^{25}$

The sample of 38 county groups is comprised of 224 counties that are highly representative of reservation counties in general. In 1960, the 13,687 Indian births in the sample represent 57 percent of all U.S. Indian live births; in 1998, the 21,158 births in the sample represent 53 percent of all U.S. Indian live births. These numbers suggest that the 38 county groups represent the majority of Native American infants born on or near reservations. $^{26}$

\subsection{Empirical Strategy}

The analysis exploits differences in the size, timing, and location of Federal sanitation projects to identify the impact of sanitation investment on infant mortality. A causal

\footnotetext{
${ }^{24}$ For a complete discussion, see the data appendix.

${ }^{25}$ For analyses of white outcomes, I remove four county groups with less than fifty white births in at least one year. Data on infant mortality for Menominee County, WI, is unavailable for 1960-61 and the county group is omitted in those years as a result.

${ }^{26}$ The fraction Native Americans living on or near reservations is estimated to have fallen from threequarters to less than one-half over the period. The fraction of urban Indian births increased from 28 to 46 percent. Although most reservations are rural, a few reservations are located within the boundaries of metropolitan areas. Births in reservation counties and urban births are not mutually exclusive.
} 
interpretation of the analysis requires that, net of the control variables, the timing of sanitation projects is uncorrelated with other factors that are likely to affect infant health. As described in Section 1, the allocation of projects is based primarily on need and annual Congressional appropriations. The level of sanitation deficiency in a county group is correlated with economic conditions on the reservation which might directly impact health. It is therefore important to control for county-group fixed effects, year fixed effects, other time-varying characteristics of places that could be correlated with health such as the number of hospitals, population growth, and a county-group-specific linear time trend. The county-group-specific time trends control for different rates of economic growth and any other unobserved slowly changing characteristics of reservations over time. Net of these controls, the exact timing of the projects is plausibly due to idiosyncratic events in the appropriation process. Every county group in the sample received at least one sanitation project over the time period. ${ }^{27}$ The effect of sanitation improvements is identified from deviations from the trend in the cumulative number of homes treated by the program per Indian household.

The basic specification takes the following form:

$$
\text { Indian IMR } R_{j t}=\beta^{*} \text { Homes }_{j, t-k}+X_{j t}{ }^{\prime} \pi+\delta_{t}+\gamma_{j}+\gamma_{j}{ }^{*} t+\varepsilon_{j t,}
$$

where Indian $I M R_{j t}$ is the Indian infant mortality rate in county group $j$ in year $t$, Homes $_{j, t}$ ${ }_{k}$ is the cumulative number of homes affected by sanitation projects completed through year $t-k$ in county group $j$ divided by the estimated number of Indian households in county group $j$ in year $t, X_{j t}$ is a vector of time-varying characteristics of county groups, $\delta_{t}$ represents individual year effects, $\gamma_{j}$ represents county group effects, and $\gamma_{j}{ }^{*} t$ represents a linear county-group-specific time trend. This framework implies that a sanitation project causes a one-time permanent shift in the infant mortality rate by $k$ years after its completion. I weight the regressions by the number of Indian households in 1980 to improve precision.

\footnotetext{
${ }^{27}$ The one county group in upstate New York that received no projects is excluded.
} 
The dependent variable in the analysis is the Indian infant mortality rate (IMR). As is common in the literature, the Indian IMR is constructed by dividing the number of Indian infant deaths in the county group in year $t$ (regardless of the birth year) by the number of thousands of Indian live births in year $t$. In other words, the infant mortality rate is the number of infant deaths per thousand live births. Linked birth-death data are unavailable for many years in the sample period and are not used in the analysis.

I discuss the sanitation treatment variable, Homes, in the following section. In addition to the county fixed effects, year fixed effects, and county-specific linear time trend, I include two control variables. The number of Indian Health Service hospitals last year is a control for the effect of hospital care on infant mortality and any effects of hospitals on the recording of births and deaths. ${ }^{28}$ Because most hospital construction activity was in the 1960s, this is the time period for which the estimate will be identified. Ideally, one would want to control for other health inputs such as health clinics, but reliable data are unavailable. The log of the estimated number of Indian households is also controlled for in all regressions.

The unit of observation is the county-group-year. ${ }^{29}$ Table 1 describes the variables used in the analysis, weighted by the estimated number of Indian households in 1980. In an average county group-year, there are around 4,500 Indian births and an Indian infant mortality rate of 20.2 per thousand. The treatment variable, Homes, is described in the next section.

\subsection{The Treatment Variable and the Timing of Projects}

The independent variable of interest, Homes $_{j, t-k}$, is a measure of intensity of sanitation investment. In particular, it is the cumulative number of homes affected by completed

\footnotetext{
${ }^{28}$ I have considered alternative measures of hospital care such as the number of hospitals per square mile and the number of beds. The number of hospitals last year is the most reliable predictor of infant mortality. An additional HIS hospital is associated with a statistically significant reduction of 1.27 deaths per 1000 births. However, due to the issues described in the introduction, the estimated effects may not be causal, so I do not emphasize them here.

${ }^{29}$ As noted by Bertrand, Duflo and Mullainathan (2002), failing to account for serial correlation when computing standard errors may lead to over-rejection of the null hypothesis. I allow for correlated errors within county groups over time by clustering at the county group level.
} 
SFC projects in county group $j$ as of year $t-k$ divided by the estimated number of Indian households in country group $j$ in year $t$. Loosely speaking, this is an estimate of the fraction of Indian homes with sanitation provided by the program as of $k$ years ago. ${ }^{30}$ Depreciation of sanitation investments is ignored, a reasonable assumption given the low depreciation rate and the fact that the analysis will exploit sudden changes in the number of homes treated by the program. ${ }^{31}$

It is not obvious at what point in time one should evaluate the effect of completed projects (or, equivalently, what value $k$ should take in the analysis). For some multi-year projects, the improvements in sanitation begin prior to the completion date. ${ }^{32}$ On the other hand, some health benefits might be expected to take several years to be realized from the time of the intervention. A project that pipes water into a home might generate changes in hand-washing habits over time, for example, in turn leading to gradual improvements in health. In addition, health externalities may be slow to be realized because person-to-person transmission is not instantaneous. Indeed, Cutler and Miller (2005) find that mortality reductions following water treatment in U.S. cities peak about five years after the interventions. In the next section, I will present results using a number of different values of $k$, and will use a lag of three years $(k=3)$ as the base specification for the remaining analyses.

Figure 2 illustrates the pattern of the Homes $_{j, t-3}$ variable for the ten largest county groups as measured by the Indian population in 1980. The effect of the program is identified by the differential timing of deviations from trend across county groups. As can be seen in the figure, several county groups have sharp jumps in the fraction of homes affected by a project in particular years. These jumps help to identify the effect of sanitation; a county

\footnotetext{
${ }^{30}$ In practice, homes may be the beneficiaries of multiple projects over time, and the cumulative number of homes treated by the program may exceed the estimated number of households. The denominator of the variable is interpolated between decennial Census years because annual population measures are unavailable. I also control for the log of the estimated number of Indian households. There is a further discussion of this issue in the data appendix.

${ }^{31}$ I will consider depreciation when I estimate project costs in Section 5.

${ }^{32}$ The extent to which benefits might be expected prior to the completion date depends on the type of project. For example, the completion of a village water treatment plant might improve water quality at a discrete point in time, whereas the extension of a water line to a number of houses each year over several years has a gradual effect. Unfortunately the data does not allow me to distinguish between these types of projects. Recall that projects lasting more than five years are excluded from the sample.
} 
group with a smooth linear increase in the Homes variable does not have any variation to exploit after controlling for the county-specific linear time trend. Within each geographic area there is substantial variation in the timing and degree of sanitation interventions. The weighted mean annual increase in the Homes variable is 0.04 , with a standard deviation of 0.14 .

The Homes variable represents the fraction of homes receiving treatment rather than the fraction of homes with sanitation. Although data on sanitation levels is unavailable on an annual basis, a rough estimate of the number of homes with sanitation can be generated using the IPUMS census microdata. ${ }^{33}$ Treating 10 percent of Indian homes in a state appears to raise the fraction with complete plumbing by 2.15 percent. Thus, to gauge the impact of complete plumbing, the estimates presented below should by multiplied by 4.65 .

The Homes variable may decline over time if the estimated number of households increases more quickly than the number of homes receiving sanitation projects. Deviations from a linear trend in the number of households may be a cause for concern if these deviations are associated with other changes at the local level such as economic growth. Therefore, I control for the log of the estimated number of Indian households in all regressions.

\section{Results}

\subsection{Main Results}

As noted above, the appropriate time to evaluate the effect of projects is ambiguous. Empirically, the effect of projects is likely to be more precisely estimated close to the completion date. There is also less potential for contamination from people moving in and out of areas. On the other hand, the full benefit of the project may not be realized for

\footnotetext{
${ }^{33}$ I use IPUMS data for Census years 1960-2000 and perform an analysis at the state level for states included in this study. The dependent variable is the fraction of Indian households with complete plumbing in the state. The key independent variable is the cumulative fraction of Indian households receiving projects completed by last year. I also control for year fixed effects, state fixed effects, and the number of Indian households. The coefficient of 0.215 is statistically significant.
} 
several years. Table 2 shows coefficients from separate regressions estimating equation (1) using a number of different positive and negative values for $k$, where a negative value implies a lead and a positive value implies a lag. The weighted least squares regressions include year fixed effects, county-group fixed effects, a county-group-specific time trend, the log of the number of Indian households, and the number of Indian hospitals last year.

The number of homes completed three years ago $(k=3)$ is used in the preferred specification, which a priori seems to be a reasonable trade-off between capturing the full benefit of the program and generating a precise and unbiased coefficient. This choice yields a large and statistically coefficient of -5.09 . In other words, a ten percentage point increase in the fraction of homes receiving sanitation projects is associated with a reduction in 0.51 deaths per thousand births by three years after the project's completion. The implied elasticity is -0.14 . As described in Section 3.3, the coefficient also implies that a ten percentage point increase in the fraction of homes with complete plumbing is associated with a reduction of 2.4 deaths per 1000 births. $^{34}$

Coefficients from separate regressions using various values of $k$ are plotted in Figure $3 b$. All values of $k$ between two and seven (that is, two to seven year lags) give negative coefficients which are significant at the 10 percent level. There is some reduction in infant mortality in anticipation of project completion, but it is not statistically significant. In the analyses to follow, regressions using the $k=3$ specification are discussed and it is noted when the substance of the results is sensitive to choosing this rather than $k=2$ or $k=4$.

It is instructive to perform an analogous analysis using the appropriation date rather than the completion date. The specification is:

$$
\text { Indian } I M R_{j t}=\beta^{*} A p p_{j, t-k}+X_{j t}{ }^{\prime} \pi+\delta_{t}+\gamma_{j}+\gamma_{j}{ }^{*} t+\varepsilon_{j t,}
$$

\footnotetext{
${ }^{34}$ The results are sensitive to weighting and the coefficient is insignificant in an unweighted regression. This is unsurprising given the low numbers of births in some observations.
} 
where $A p p_{j, t-k}$ is the cumulative number of homes affected by appropriated SFC projects in county group $j$ as of year $t-k$ divided by the estimated number of Indian households in country group $j$ in year $t$.

Column II of Table 2 reports coefficients from separate regressions estimating equation (2) using various negative values of $k$ (points before the appropriation date) and positive values of $k$ (points after the appropriation date). The coefficients and confidence intervals are plotted in Figure 3a. This can be viewed as a falsification exercise. The results show that infant mortality does not significantly deviate from trend prior to appropriation. Furthermore, if one includes lead and lag variables in one regression (not shown), the lead variables are not jointly significant. ${ }^{35}$ This is suggestive evidence that the precise timing of sanitation projects is not correlated with other determinants of infant mortality, net of the control variables. It is worth noting that the base specification compares infant mortality to a linear trend over many years rather than to the period just prior to an intervention, so mean reversion is less of a concern here than in many program evaluation contexts.

Table 3 examines the effect of sanitation projects by age of mortality. Columns II and III demonstrate that the effect of sanitation stems from a reduction in post-neonatal deaths rather than neonatal deaths. Evaluated at weighted sample means, the implied elasticity of post-neonatal mortality with respect to sanitation investments is -0.24 . As expected, the effect of sanitation on neonatal mortality is small.

An additional Indian Health Service hospital is associated with a reduction in infant mortality on the order of 1.3 per 1000 births. As in the case of sanitation, most of the reduction is in post-neonatal deaths. This is unsurprising given the fact that the variation identifying the effect is largely from changes in the 1960s. It was not until the mid-1970s that hospitals made significant gains in care for premature infants which would be expected to affect neonatal mortality (Cutler and Meara, 1997). The estimates imply that

\footnotetext{
${ }^{35}$ If one includes eight leads and nine lags from the appropriation date in a single regression, an F-test for the joint significance of the eight lead variables $(\mathrm{k}=-1$ through $\mathrm{k}=-8)$ leads yields a $\mathrm{p}$-value of 0.12 . F-tests for the joint significance of six and four lead variables yield p-values of 0.32 and 0.40 respectively. In contrast, the joint test of the nine lag variables $(\mathrm{k}=1$ to $\mathrm{k}=9$ ) yields a $\mathrm{p}$-value $<0.01$.
} 
the reduction in infant mortality from the construction of a new hospital was similar to that of a sanitation project affecting 25 percent of the homes in an area. However, there are several reasons to be cautious in the interpretation of the coefficient on the hospitals variable. There are only a small number of changes during the sample period. In addition, hospital construction appears to be concentrated in areas with high pre-existing infant mortality rates relative to trend. Finally, the presence of an Indian Health Service hospital may affect the likelihood of birth and death reporting as well as the coding of race. ${ }^{36}$ I focus on the sanitation interventions for the remainder of the analysis.

\subsection{Sanitation and Infant Mortality by Disease}

Table 4 investigates the impact of sanitation investment on the infant mortality rate by disease. The table presents coefficients from separate regressions, each of which includes county fixed effects, year fixed effects, a county-group specific linear time trend, and a control for the number of hospitals in the previous year. Because the sample period covers three disease coding regimes, I use a disease coding crosswalk for infant diseases described by MacDorman and Rosenberg (1993). For completeness, I report results for all of the categories they list, although they do not consider all to be comparable over time. $^{37}$

I also report coefficients on two disease categories I create based on information on communicable diseases in Chin (2000). The "gastrointestinal" disease category includes most of the illnesses specified in the "certain gastrointestinal" category suggested by MacDorman and Rosenberg, as well as a number of infectious diseases likely to be affected by sanitation such as typhoid, paratyphoid, and cholera. Chin (2000) includes the provision of adequate sanitation as a preventative measure for these diseases, which are generally transmitted through the fecal-oral pathway. The "infectious respiratory" category includes pneumonia, influenza, whooping cough, and bronchitis. Chin (2000) reports that these diseases are spread by person-to-person transmission. The "diseases

\footnotetext{
${ }^{36}$ IHS hospitals may increase the likelihood that an infant is coded as "Indian" at birth or death. It is also possible that births and deaths in isolated areas would be more likely to be recorded because they would be more likely to take place in a hospital.

${ }^{37}$ In the case of SIDS, they suggest no early coding category and I include this as zero. See the data appendix for more information on disease coding.
} 
related to sanitation" category is the combination of the "gastrointestinal" and "infectious respiratory" categories I created. The "diseases not related to sanitation" category is a combination of all the disease categories listed by MacDorman and Rosenberg (1993) except for the "certain gastrointestinal" and "pneumonia and influenza" categories. The categorization is not intended to be absolute. ${ }^{38}$

About than three quarters of the observed effect of sanitation on infant mortality can be attributed to diseases that one would expect to be related to sanitation a priori. Sanitation has a sizeable effect on both gastrointestinal disease and infectious respiratory disease. The implied elasticities are just over -0.5 for both categories evaluated at weighted sample means. Similar effects are found for the MacDorman and Rosenberg categories "certain gastrointestinal" and "pneumonia and influenza". As expected, most other disease categories show no significant correlation with the timing of sanitation projects, and there is no significant effect of sanitation on mortality from all causes other than GI and infectious respiratory diseases. ${ }^{39}$

Recall that two distinct mechanisms mediate the impact of sanitation on the two disease categories. Gastrointestinal illness tends to be ameliorated by improvements in water quality, largely determined by the sanitation system. Respiratory disease is likely to be impacted by the level of water use and cleanliness in the community. The results suggest that the biological impact of clean water and the behavioral response induced by the reduced price of water are both important factors contributing to the observed infant mortality decline. ${ }^{40}$

\subsection{Heterogeneous Treatment Effects}

The effect of sanitation investment may vary by the level of pre-existing sanitation infrastructure. With functional water and sewer facilities in place, new projects may be

\footnotetext{
${ }^{38}$ For example, a number of infectious diseases could affect infant health in utero and could be associated with subsequent complications after birth.

${ }^{39}$ Exceptions are the rate of death from accidents and respiratory distress syndrome. These results are probably spurious, but could be indirectly related to sanitation improvements.

${ }^{40}$ An alternative interpretation is that the improved water quality reduced gastrointestinal disease, which in turn limited susceptibility to other types of disease.
} 
less likely to have a discrete measurable impact on infant mortality. Two tests are performed to examine this idea. The treatment variable is allowed to vary by the cumulative level of treatment and by the year of the project.

In column II of Table 5, I examine the effect of the treatment variable interacted with dummy variables indicating whether the variable takes a value less than 1 or at least 1 . Thus, the categories loosely correspond to the first project per household and subsequent projects. $^{41}$ Initial projects are associated with a four times larger drop in infant mortality than subsequent projects. ${ }^{42}$ Column III reports coefficients on the treatment variable interacted with dummies representing three time periods: before 1973, 1973-1985, and after 1985. The analysis does not have the power to justify a strong claim about the pattern of treatment effects over time. Nevertheless, the pattern of coefficients suggest that effect of the program on infant mortality declined as the sanitation on reservations improved. In recent years, many IHS sanitation projects involve replacing and improving infrastructure built in the 1960s and 1970s. It would be surprising if these projects generated as sharp changes in infant mortality as their predecessors did. If more recent projects prevent the gradual depreciation and obsolescence of existing infrastructure, they may well have a long-run health benefit that would not be captured by the analysis performed here.

I perform a number of robustness checks which are not described in detail here. The general conclusion is that the results presented are quite robust. ${ }^{43}$ As a further check, I

\footnotetext{
${ }^{41}$ Of course, this is a simplification because projects may be distributed unevenly within county groups.

${ }^{42}$ The difference in coefficients is statistically significant. Almost $90 \%$ of observations fall into the Homes $<1$ category.

43 Although it is difficult to find data dating back to 1960, a number of annual control variables are available for the years 1969-1998. I use several variables constructed from the Natality Detail files, such as weight at birth, age of mother, the log of the number of births, and the log of the number of births squared. I also consider variables from the Regional Economic Information System (REIS): log per capita income, the employment to population ratio, transfer payments per capita, and medical assistance payments per capita. The REIS variables are not race-specific. The inclusion of all controls slightly reduces the estimated effect of sanitation investment for the 1969-1998 period, but the coefficient remains statistically significant (results not shown). I also consider the impact of dropping each county group from the regression one by one (results not shown). The coefficient of interest is always negative and almost always statistically significant. The one exception is the case when the county group including Choctaw, OK is omitted, the coefficient is -2.03 and significance falls to the 17 percent level. Finally, I run all regressions using alternative evaluation dates of $k=2$ and $k=4$. The conclusions pertaining to Indian infant mortality are unaffected. For further details regarding robustness checks, please contact the author.
} 
run a specification for 1969-1998 with the fraction low birth weight as the dependent variable. There is no statistical relationship between the fraction low birth weight and the treatment variable. The same is true for the fraction very low birth weight. Similarly, no relationship is found between the fraction of mothers that are less than 20 or over 35 and the treatment variable after including a full set of controls. These results (not shown) support the notion that the mortality reduction is not stemming from a change in the composition of births.

If sanitation affects infant mortality, it probably affects other health outcomes as well. I am not able to detect a statistically significant relationship between the timing of sanitation projects and mortality of other age groups (analysis not shown). This does not rule out the possibility, however, that sanitation investments improve health beyond the effect on infant mortality. ${ }^{44}$

\subsection{Externalities of Sanitation Projects}

The effect of the SFC sanitation interventions on neighboring white infants is of interest. White infants are potentially affected by the SFC program in several ways. First, white infants might receive direct services from the program. For example, if a sanitation project improves the water filtration system for a town, all households in the town would benefit regardless of race. White infants might also live in a household with a Native American person eligible for services from the SFC program. ${ }^{45}$ Finally, Indian infants receiving the intervention might be coded as white infants in the mortality data.

\footnotetext{
${ }^{44}$ By improving the disease environment, sanitation probably reduces the incidence of non-fatal infectious disease. This hypothesis cannot be tested with the available data. However, it is worth noting that the costs of morbidity associated with infectious disease are high, even in the absence of fatalities. A study of two villages on the Hopi Reservation in the 1960s found that the average infant visited a doctor 2-3 times for diarrhea-related illness (Rubenstein et al., 1969). ${ }^{44}$ More recent studies find much lower rates of illness, and continued declines since 1980 (Holman et al., 1999). ${ }^{44}$ Even in the recent period, however, the average diarrhea-related hospitalization for children under 5 lasted 2-4 days. The disruption associated with infectious disease suggests that even a modest improvement could make a substantial difference in the lives of children and their caretakers.

${ }^{45}$ Intermarriage rates between individuals describing themselves as "white" and "Native American" are quite high, although they may be lower in the reservation areas under study here.
} 
Second, white infants could benefit from the externality generated by healthier Native Americans in their communities. As noted in Section 2, these health benefits can be separated into two types of effects. If white households lack a clean water source, improvements to their neighbor's sewerage would reduce their exposure to gastrointestinal disease. In addition, if water use of Native American households increases, the entire community would be less exposed to diseases transmitted by air or personal contact such as respiratory disease. The fact that whites are not directly targeted by the SFC program provides a nice opportunity to study health externalities.

Table 6 reports an analysis similar to that in equation (1) examining the effect of the intervention on the white infant mortality rate by disease. ${ }^{46}$ There is a marginally statistically significant effect of the SFC interventions on mortality of white infants from a reduction in infectious respiratory disease (see column I). The implied elasticity is -0.3 . The magnitude of the reduction in is an order of magnitude smaller than the effect on Indian infants, yet is too large to be plausibly due to inconsistent coding of race. ${ }^{47}$ The smaller effect of sanitation on GI disease (column IV) is unsurprising given the low initial levels of gastrointestinal disease among white infants. ${ }^{48}$ The evidence points to a general improvement in the disease environment affecting respiratory disease levels among whites. As described in Section 2, increased household water consumption and cleanliness on the part of direct beneficiaries of the program could spill over into a healthier environment for the entire community.

\footnotetext{
${ }^{46}$ For precision, I weight by the number of white households in 1980 and exclude three county groups with less than 50 white births in a year. I also control for the log of white households as well as all other variables previously included.

${ }^{47}$ As discussed in the data appendix, about thirty percent of infants coded as Indian at birth are coded as white at death. Because whites are a much larger group in the population, the reverse is not true. If the ratio of Indian to White births in area is 10:1 and the observed reduction in respiratory deaths among Indians is 2.50 per 1000 Indian births, a reduction in the white respiratory infant mortality rate of 0.075 per thousand could plausibly be explained by inconsistent coding. The observed rate reduction is 0.49 per 1000. The relative group sizes could also affect the degree of miscoding. It is possible that the measures of exposure and density in Table 6 are correlated with miscoding, though it is impossible to know how severe the miscoding is in different areas. These regressions should be considered suggestive.

${ }^{48}$ The implied elasticity for white gastrointestinal mortality is -0.4. There is a statistically significant effect of sanitation on white gastrointestinal mortality in the earliest period (before 1973, results not shown). An effect on gastrointestinal mortality is also detectible if one uses $k=2$ or $k=4$ rather than $k=3$. In addition, there is statistically detectible effect on disease categories not related to sanitation, though the elasticity is small. No individual disease category in this group shows a statistically significant effect (results not shown).
} 
One implication of the health externality hypothesis is that white infants should experience greater sensitivity to sanitation improvements if their household is in close contact with Indian households. Because detailed data on residential location by race is unavailable at the beginning of this time period, I use two imperfect measures of the proximity of white households to Indian households. First, I consider a common integration index: the exposure index. The exposure index ranges from 0 to 1 and is a measure of the average fraction of Indian households in the typical white household's Census tract. The measure is based on 2000 Census data, which is not ideal because residential patterns are potentially determined by sanitation investment. However, the exposure index is a reasonable measure of integration if residential patterns are persistent over time. ${ }^{49}$ The second proxy for residential exposure is a measure of density, the number of Native Americans in 1980 per square mile. Each of these variables is interacted with the treatment variable.

The results shown in columns II to IV of Table 6 indicate that the beneficial effect of sanitation investment on white respiratory disease is strongest in places where white households have greater levels of residential exposure to Indian households. This is true using the exposure index or density as an indicator of residential exposure. The results are consistent with the notion that the observed relationship between sanitation and white respiratory disease is driven by the indirect benefits of a healthier disease environment and reduced person-to-person transmission of disease. Columns VI to VIII suggest that the pattern is limited to respiratory disease. Indeed, county groups with a greater degree of integration as measured by the exposure index show less responsiveness of gastrointestinal disease to sanitation. However, the measures of exposure are imperfect and residential patterns may be correlated with other factors that influence the intensity of response to the intervention. The results should be considered suggestive. ${ }^{50}$

The effect of sanitation interventions on the sanitation-related infant mortality rate for whites is less than 15 percent of the effect for Native Americans. Nevertheless, the

\footnotetext{
${ }^{49}$ See the data appendix for information on the construction of the exposure index.

${ }^{50}$ The externality results are somewhat sensitive to the choice of evaluation date. The effect of the interaction between measures of exposure and sanitation investment on white infectious respiratory disease is sizable but statistically insignificant using a specification in which $k=4$.
} 
number of white infants affected may be quite large. On average, the number of white infants in a county group is about ten times greater than the number of Indian infants. Thus, even a small reduction in the white infant mortality rate may result in the survival of a greater number of white infants than Native American infants. This issue is revisited in Section 5.

The evidence presented here is suggestive of an externality onto the health of white infants not directly treated by the program. An alternative hypothesis is that the apparent effects on white infants represent deviations from the place-specific linear time trend that result from common shocks to a county group. If one considers white infants to be a control group in the analysis of Indian infant mortality, the estimated effects are only slightly smaller than those reported in Section 4.2 and are statistically significant at the ten percent level (results not shown).

\section{Implications}

\subsection{Contribution of the Interventions to Indian Infant Mortality Declines and Indian-White Convergence}

What would have happened if the sanitation projects had never occurred? One can use the estimated coefficients in the model to simulate what would have happened in the absence of the intervention if other factors were unchanged. ${ }^{51}$ In sample areas, sanitation interventions are responsible for about 16 percent of the overall decline in the Indian infant mortality rates. Holding other factors constant, the typical Indian infant mortality rate would be 51 percent higher today, or 14.1 per 1000, in sample areas had the SFC program never existed. The estimates suggest that sanitation explains 17 percent of narrowing of the Indian-white infant mortality gap in sample areas since 1960 and 40 percent since 1970, including the estimated effects on white infants.

\footnotetext{
${ }^{51}$ I use the estimated regression coefficients from the model to predict the infant mortality rate if the fraction of homes treated equals zero. This exercise is a conservative estimate of the total effect of the program because some of the benefits may be absorbed by the year effects and the county group-specific time trend. Note that the gap described is estimated for the typical reservation (weighted by Indian households in 1980). I compare the average rate in 1960-1962 to the average rate in 1996-1998. The numbers presented here are slightly different than those in Figure 1 because Figure 1 is implicitly weighted by the number of live births rather than households in 1980 .
} 


\subsection{The Cost of Saving A Baby}

By comparing the costs of a sanitation project to its effect on infant mortality, one can develop a crude estimate of the cost per infant "saved," i.e. the expenditure per infant that would have died in the absence of the program. This exercise requires several assumptions. First, I make the conservative assumption that the observed impact on two categories of infectious disease, gastrointestinal and infectious respiratory diseases, accurately reflects the total change in infant mortality due to a sanitation intervention. In other words, a 10 percentage point increase in the fraction of homes with sanitation causes an extra 0.380 per 1000 Indian infants and an extra 0.063 per 1000 white infants to survive annually (or 1.70 Indian and 2.24 white infants in a typical county group). Assume that if the sanitation facility is maintained, the benefits accrue in perpetuity. The annual cost to maintain the structure is based on an estimated depreciation rate of 1.5 percent. ${ }^{52}$ The cost of projects is calculated using the total SFC budget for the year and so includes all administrative costs associated with the program. ${ }^{53}$ I assume that the survival of infants born in the future is worth somewhat less than the survival of those today, using a discount rate of 5 percent. The (weighted) average cost of treating one home is $\$ 2,407$ (in 2000 dollars). The cost of the intervention per "present discounted infant" saved is about $\$ 217,000$ if one combines the benefits to white and Indian infants. ${ }^{54}$

If one assumes that an infant surviving as the result of sanitation would live a healthy life to age 60 , the cost per discounted life-year is just over $\$ 7,000$. Although this estimate is rough, it gives a sense of the cost-effectiveness of the program. Typically, economic studies estimate the value of a healthy life year at about $\$ 75,000$ to $\$ 150,000$ (Cutler and Meara, 1999) and a value of a life between $\$ 1$ and 7 million (Viscusi, 1993, and

\footnotetext{
${ }^{52}$ According to the Bureau of Economic Analysis Fixed Assets Tables, the average annual depreciation rate for government sewer system structures and water supply facilities over the 1960-1998 period is just under 1.5 percent.

${ }^{53}$ The marginal cost associated with an average project is much lower.

${ }^{54}$ Because the coefficients are based on weighted regressions, the means used in these calculations are also weighted. The number of Indian homes in a county group is 36,659. A 10 percentage point increase in the number of homes treated is 3,666. At an average cost per home of \$2407 (2000 dollars), an intervention costs $\$ 8.82$ million plus $\$ 2.78$ in present discounted costs of maintenance. The intervention saves 1.7 Indian and 2.2 white infants annually, or about 83 infants total The cost per present discounted infant is about $\$ 140,000$. I ignore the cost of collecting public funds.
} 
Ashenfelter and Greenstone, 2004). By this metric, the return to sanitation investment is very high even if reductions in infant mortality are the only benefit. ${ }^{55}$ However, it is not clear that these numbers are appropriate for infants. The value of a life-year for infants may be somewhat lower because relatively few investments have been made in them.

Alternatively, one might compare these numbers to the cost of other infant health interventions. Cutler and Meara (1999) estimate that spending an additional $\$ 40,000$ per low birth weight infant increased survival by 11.8 years on average, or 10.5 qualityadjusted life years (QALYs). If these life years are discounted using a comparable methodology to the one above, the cost per life year is just over $\$ 11,000 .^{56}$ The cost of sanitation interventions appears to be comparable to, and likely lower than, the cost of neonatal intensive care in saving infant lives. Both of these interventions are much cheaper than targeted expansion of Medicaid insurance coverage. Currie and Gruber (1996) estimate that offering public health insurance to the poor improves infant survival at a price of $\$ 840,000$ per infant, a cost several times higher than sanitation investment.

A full cost-benefit analysis of investment in sanitation would require an accurate valuation of an infant life as well as other benefits of the interventions. For every additional infant that survives, it is likely that many more experience reductions in days of illness. General health benefits probably accrue to older children and adults as well. These, in turn, may improve long run economic outcomes. The reduced burden of carrying water and quality of life improvements are additional benefits of the sanitation interventions not considered here.

\section{Conclusions}

In 1960, more than five percent of Indian infants living in reservation counties died in the first year of life. Today the Indian infant mortality rate stands at less than one percent in those same areas, and the Indian-white infant mortality gap has dramatically narrowed.

\footnotetext{
${ }^{55}$ Cutler and Miller find that sanitation improvements in the U.S. in the early $20^{\text {th }}$ century were even more cost-effective, with a cost of only $\$ 500$ per life-year.

${ }^{56}$ In other words, I assume that these additional life years accrue over a 60 -year period and discount them at a rate of 5 percent. Also note that, in contrast to the study of premature infants, it is reasonable to assume that infants affected by the sanitation intervention would lead healthy lives if they survived.
} 
In the interim, the Indian Health Service invested an average of $\$ 80$ million annually in sanitation. This study exploits variation in the timing of sanitation to provide a quasiexperimental estimate of the causal impact of these health inputs on infant mortality.

I find that a ten percentage point increase in the fraction of homes with sanitation improvements reduced infant mortality by 0.51 per 1000 births. The Sanitation Facilities Construction program can explain about forty percent of the convergence since 1970. Indian infant mortality in sample areas would be about 50 percent higher in the absence of the program, holding other factors constant. Sanitation investment reduced both gastrointestinal and respiratory diseases, suggesting that both drinking water quality and the behavioral response to quantity of water may have been important. The cost of saving an infant by improving sanitation is estimated at $\$ 217,000$, which is in the low end of the range of policies designed to improve infant health.

In sum, public health investment in poor rural areas appears to reduce infant mortality substantially. The evidence presented here also suggests that sanitation investment yields important health externalities. The results provide an interesting contrast to those reported in Troesken (2001). He finds a reduction in black typhoid rates arising from municipal water provision in American cities around the early $20^{\text {th }}$ century. The extension of public water services to blacks in a climate of extreme political racism is surprising. A natural explanation for the uncharacteristic public generosity towards blacks is the presence of health externalities. However, Troesken is unable to find evidence supporting the presence of externalities across racial groups in his data.

The intervention described in this paper is less puzzling. By the 1960s, altruism might have been adequate to motivate Federal sanitation provision to Indians. Nevertheless, I do find evidence suggesting that health benefits accrue to whites. These spillovers appear to stem from an improved disease environment generally, rather than from a direct change in water quality in white households. The declines in the white infant mortality rate are small. However, the number of white infants surviving as the result of the program is slightly greater than the number of Indian infants because of the relative sizes 
of the two groups. Thus, the benefits would probably be large enough to justify Federal intervention even if the Federal government only valued white outcomes. ${ }^{57}$

The congressional testimony surrounding the adoption the SFC Act speaks to the issue. The language is generally altruistic and paternalistic in tone, emphasizing the severe deprivation of the Indian people. Nevertheless, one witness from an Indian advocacy group did make the following case for Federal investment in sanitation:

One other factor that cannot be emphasized too strongly...is that poor sanitation facilities on Indian reservations have a direct effect upon the health of the surrounding non-Indian communities. You cannot quarantine these diseases; you cannot quarantine polluted streams; you cannot quarantine flies, they get from one place to the other. And when an effort is made to improve sanitation facilities on Indian reservations, we are, in fact, performing a service for non-Indian communities in the same area....So in those terms I think that this is merely legislation for the general welfare. ${ }^{58}$

Although perhaps not the primary motivation of the legislation, the potential for health benefits to whites was recognized at the program's inception. ${ }^{59}$

The analysis also sheds light on one reason why tribes might have chosen not to invest in sanitation facilities prior to the SFC Program. Indians receive only a fraction of the returns to sanitation projects. Although the cost of sanitation per infant saved is reasonable compared to other investments, the cost per Indian infant is about 325,000 dollars. ${ }^{60}$ Even with perfect credit and information, and a well-functioning government, it seems likely that a poor tribe in the 1950 s would have chosen to invest its scarce resources elsewhere. ${ }^{61}$

\footnotetext{
${ }^{57}$ As early as 1802, the Federal government attempted to control infectious disease among Indians living near American military outposts. It is highly improbable that the motivation was altruistic.

${ }^{58}$ Published hearings for May 5-6, 1959, House of Representatives, Committee on Interstate and Foreign Commerce, Subcommittee on Health and Safety, testimony of Arthur Lazarus of the Association on American Indian Affairs, p. 68-69.

${ }^{59}$ Bergman, Grossman and Erdrich (1999) note that Senator Alan Bible (D-Nev.) had received complaints from some white constituents about contamination of their water supply from tribal lands.

${ }^{60}$ I repeat the exercise performed in Section 5.

${ }^{61}$ As noted in the introduction, there are also reasons to believe that there were failures in credit, information, and/or tribal governance.
} 
The presence of significant health externalities suggests that the public sector has an important role to play in allocating resources to sanitation. In the context of the Sanitation Facilities Construction program, the intervention also narrowed interracial health differentials, but that need not be the case. A health intervention targeted at a small disadvantaged group could increase health differentials if the health externalities were very large. 


\section{Data Appendix}

\subsection{Natality Data}

Natality Data for 1968-1988 come from publicly available Natality files from the National Center for Health Statistics. These files contain either a $50 \%$ or $100 \%$ sample of detailed records of all births from all states. Similar data for 1989-1998 is available with permission from the NCHS and contains confidential county identifiers for every birth in the United States. I exploit available data on weight at birth and age of mother. Data on the number of live births by county by race prior to 1968 has been collected and handentered where necessary from a subset of individual states (CA, ID, MN (partial), MT, NE, OK, OR,SD, WA, and WI). Of the 224 counties represented in the final sample, natality data is available for 1965 onwards for 149 counties and complete data 1960-1998 is available for 137 counties. The data is complete for 23 of 38 county groups. In Oregon in 1961, the category other non-white includes Indians and others; in this case the number of Indian births is estimated assuming Indians represent the same fraction of nonwhite non-black births as the average for 1960 and 1962. Data is unavailable for Menominee, WI prior to 1962 and the county group is excluded from the analysis for those two years. Otherwise, the number of live births by race for 1960-1967 for counties lacking published data is assumed to be the same as that for the earliest available data (typically data from 1968). For counties in which data is available, there is no statistically significant trend in the numbers of Indian births over the years 1960-1967.

\subsection{Mortality Data}

Mortality Data for 1968-1988 come from publicly available Mortality Detail files from the National Center for Health Statistics. The files contain a 100\% sample of all deaths starting in 1973 and a partial sample in earlier years. Similar data for 1989-1998 is available with permission from the NCHS and contains confidential county identifiers for every birth in the United States. Unpublished data was obtained from the NCHS for the years 1959-1967. Every county and year includes mortality data with the exception of Menominee, WI prior to 1962; in that case the years prior to 1962 are excluded from the sample.

\subsection{Cause of Death}

The mortality data includes cause of death codes. Data for the years 1960-1967 uses the ICD-7 classification, for the years 1968-1978 uses the ICD-8 classification, and for the years 1979-1998 uses the ICD-9 classifications.

As used in this paper, gastrointestinal disease refers to the following diseases described in ICD-9 and their equivalents in earlier years: Cholera, Typhoid and Paratyphoid fevers, Other Salmonella infections, Shigellosis, Other food poisoning, Amebiasis, Other protozoal intestinal diseases, Intestinal infections due to other organisms, Regional enteritis, Idiopathic procolititis, Vascular insufficiency of intestine, Other noninfectious gastroenteritis and colitis, Perinatal disorders of the digestive system, and Symptoms involving digestive system.

The following are included in the Infectious Respiratory Category: Whooping Cough, Acute Bronchitis and Bronchiolitis, Viral Pneumonia, Pneumococcal Pneumonia, Other bacterial Pneumonia, Pneumonia due to other unspecified organism, Pneumonia in infectious diseases classified elsewhere, Pneumonia organism unspecified, Influenza, Bronchitis not specified, Chronic Bronchitis, and Pneumonia of the fetus and newborn.

The other diseases categories are those described in the crosswalk of infant mortality categories in the appendix of MacDorman and Rosenberg (1993), p.50. For completeness, I include every disease category they list, although some are not considered sufficiently comparable for trend analysis.

\subsection{Age}

Infant deaths are those that occur at less than one year of age. Neonatal deaths are those occurring at less than 28 days of age. Post-neonatal deaths are those occurring between 28 days and 11 months of age. 
Deaths at an unspecified number of days or weeks are considered neonatal; those at an unspecified number of months are considered post-neonatal.

\subsection{Race}

Race codes in the vital statistics data are problematic. Newborn infants are assigned a race based on an algorithim of their parents' races prior to 1989. Starting in 1989 births are coded by race of mother. For data collected from individual states on the number of live births by county by race for 1960-1967 the method of assigning race varied.

Hahn, Mulinare, and Teutsch (1992) note a high level of discrepancy between race of infants at birth and at death in a study of matched vital statistics data for 1983-1985. More than a third of infants coded "Indian" at birth are coded "White" at death. The reverse is rarely true; infants coded "White" at birth are coded "Indian" at death one tenth of one percent of the time. This fact leads to a systematic understatement of the Indian infant mortality rate. Because Indians are such a small group, it does not have a sizable impact on the estimated white infant mortality rate.

\subsection{Sanitation Data and Project Selection Criteria}

Sanitation project data was provided courtesy of the Indian Health Service Sanitation Facilities Construction Program, Department of Environmental Health and Engineering. The database consists of more than 10,000 sanitation projects constructed in the years 1959 to the present. Variables include IHS area, project name, number of homes affected, cost of project, and sometimes identification of the reservation and tribe. In cases lacking information on reservation, the project name was used to identify the reservation wherever possible. In total, about 85 percent of projects were successfully matched to a reservation and/or county. Projects that could not be matched were discarded.

A number of sanitation projects were excluded from the sample. First, I excluded projects that were labeled emergency, special, urban, training, operations and management, or appeared to be for facilities rather than homes. I also eliminated projects for which the location was ambiguous or the completion date was missing. This results in 5,804 projects. Eliminating projects greater than five years in duration and one project fopr which the appropriation year was more than one year after the completion year results in 5,406 projects.

A second round of selection is based on location. I eliminate projects in Alaska and in county groups with less than 50 Indian births in at least one sample year. The final data set contains 3,700 projects.

\subsection{Hospital data}

Information on hospitals is available from the American Hospital Association (AHA). I use biannual electronic files for the years 1970-1984 and annual files for the years 1986-2000. These files are matched to the "Guide Issue" published by the AHA for the years 1966 and 1968. For odd years 1969-1985, I assume a hospital was in existence if it was in existence the subsequent year. For years prior to 1966, I use information from the U.S. Public Health Service's Health Care Facilities Engineering Millennium Report (2000). This publication includes hospital construction dates for Indian Health Service hospitals built since the mid-1950s. However, it does not always distinguish between new hospitals and replacement hospitals. If a hospital operating in 1966 according to the AHA sources is not listed as having been constructed between 1957 and 1966, I assume it was in operation throughout the period.

\subsection{Construction of County Groups}


Vital statistics data provides information on county of residence, while information on sanitation projects includes the reservation. Reservations cross county lines, and some counties contain more than one reservation. To deal with this problem, I construct groups of contiguous counties such that every relevant county is in exactly one county group and every reservation is in exactly one county group. The 379 relevant counties are compressed into 138 county groups. County groups are then excluded if they have less than 50 Indian births in any year in the sample or if they never receive a sanitation project. The final analysis includes 224 counties in 38 county groups.

In 1960 and 1961, data is unavailable for Menominee County, WI because it became a county in 1962. I exclude the county group for those two years.

\subsection{Inflation adjustment}

Project costs are adjusted using the CPI-U using the 1982-1984 base year (available from the Bureau of Labor Statistics at ftp://ftp.bls.gov/pub/special.requests/cpi/cpiai.txt). All costs of projects are reported in 2000 dollars.

\subsection{Number of Households}

Annual estimates of the number of population by race by county are obtained from the U.S. Census Bureau for the years 1990 onwards, and are imputed using a constant geometric rate for each decade between decennial Census data years prior to 1990 . The number of households is estimated using national racespecific averages of the households per population for each year using the PUMS data for 1970, 1980, and 1990. The number of households per person is imputed linearly between census years.

\subsection{Exposure Index}

The exposure index is based on tract-level population data from the 2000 Census. It is based on respondents who described their race as White alone, American Indian alone, American Indian and one other race, or American Indian and two other races. The latter three categories are combined into "Indian" for the purposes of the index. Other respondents are excluded from the variable construction. A Census tract is a unit of variable area that represents about 4,000 people. The exposure of whites to Indians in a county group is the average fraction Indian in the typical white person's Census tract. The formula is:

$$
\text { Exposure }_{\mathrm{g}}=\sum_{\mathrm{t}}\left(\text { whitepop }_{\mathrm{t}} / \text { whitepop }_{\mathrm{g}}\right) *\left(\text { indianpop }_{\mathrm{t}} / \text { pop }_{\mathrm{t}}\right) \text {, }
$$

where whitepop is the white population, indianpop is the Indian population, pop is the sum of the Indian and white population, the $g$ subscript refers to a county group, and the $t$ subscript refers to a tract within the county group. For details, see Cutler, Glaeser and Vigdor (1999). The exposure index reflects both the overall fraction of Indians in the county group and their distribution across tracts. The variable has a weighted mean of 0.05 . The ideal exposure index would be based on 1960 data but historical tract-level data are not available for rural counties. 


\section{References}

Almond, Douglas V., Kenneth Chay, and Michael Greenstone, "Civil Rights, the War on Poverty, and Black-White Convergence in Infant Mortality in Mississippi," (http://elsa.berkeley.edu/ kenchay), 2003.

American Hospital Association, Journal of the American Hospital Association: Guide Issue, Part Two, 1970.

Ashenfelter, Orley and Michael Greenstone, "Using Mandated Speed Limits to Measure the Value of a Statistical Life," Journal of Political Economy, CXII (2004), pp.S226-67.

Bergman, Abraham B., David C. Grossman, and Angela M. Erdrich, et.al., "A Political History of the Indian Health Service," The Milbank Quarterly, 77(1999), pp.571-604.

Bertrand, Marianne, Esther Duflo, and Sendhil Mullainathan, "How much Should we Trust Differences-in-Differences Estimates?” NBER Working Paper No. 8841, 2002.

Bleakley, Hoyt, "Disease and Development: Evidence from Hookworm Eradication in the American South," (http://weber.ucsd.edu/ bleakley), 2002.

Chay, Kenneth Y., and Michael Greenstone, "The Convergence in Black-White Mortality Rates during the 1960s," American Economic Review, XC (2000), pp. 326-332.

Chay, Kenneth Y., and Michael Greenstone, "Air Quality, Infant Mortality, and the Clean Air Act of 1970," NBER Working Paper No.10053, 2003.

Chin, James ed., Control of Communicable Diseases Manual. (Washington DC:

American Public Health Association, 2000).

Collins, William J., and Melissa A. Thomasson, "Exploring the Racial Gap in Infant Mortality Rates, 1920-1970,” NBER Working Paper No. 8836, 2002.

Cornell, Stephen, and Joseph P. Kalt, "Where does Economic Development Really Come From? Constitutional Rule among the Contemporary Sioux and Apache," Economic Inquiry, XXXIII (1995), pp. 402-426.

Currie, Janet, and Jonathan Gruber, "Saving Babies: The Efficacy and Cost of Recent Changes in the Medicaid Eligibility of Pregnant Women," Journal of the Political Economy, CIV (1996), pp. 1263-1296.

Cutler, David M., and Ellen Meara, “The Technology of Birth: Is it Worth It?” NBER Working Paper No. 7390, 1999. 
Cutler, David M., Edward L. Glaeser, and Jacob L. Vigdor. "The Rise and Decline of the American Ghetto," Journal of Political Economy, CVII (1999), pp. 455-506.

Cutler, David M., and Ellen Meara, "The Medical Costs of the Young and Old: A Forty Year Perspective" in David Wise, ed., Frontiers in the Economics of Aging, Chicago:The University of Chicago Press, 1998, pp. 215-246.

Cutler, David and N. Grant Miller, "The Role of Public Health Improvements in Health Advances: The 20th Century United States,” Demography, XLII (2005), pp.1-22.

Department of Health and Human Services, Regional Differences in Indian Health 19981999, (http://www.ihs.gov/PublicInfo/Publications), 2002.

Department of Health and Human Services, Division of Facilities and Environmental Engineering, Criteria for the Sanitation Facilities Construction Program, June 1999.

Esrey, Steven A., James B. Potash, Leslie Roberts, and Clive Shiff, "Health Benefits from Improvements in Water Supply and Sanitation: Survey and Analysis of the Literature on Selected Diseases," Water and Sanitation for Health Project (WASH), Technical Report No. 66, prepared for the United States Agency for International Development, 1990.

Evans, William N, and Julie H. Topoleski, "The Social and Economic Impact of Native American Casinos," (http://www.bsos.umd.edu/econ/evans/), 2002.

Galiani, Sebastian, Paul Gertler, and Ernesto Schargrodsky, "Water for Life: The Impact of the Privatization of Water Services on Child Mortality," Journal of Political Economy CXIII (2005), pp.83-120.

General Accounting Office, "Economic Development Federal Assistance Programs for American Indians and Alaska Natives," GAO Report No. GAO-02-193, 2001.

Gitter, Robert J., and Patricia B. Reagan, "Reservation Wages: An Analysis of the Effects of Reservations on Employment of American Indian Men," American Economic Review, XCII (2002), pp.1160-68.

Hahn, Robert A., Joseph Mulinare, and Steven M. Teutsch. "Inconsistencies in Coding of Race and Ethnicity Between Birth and Death in US Infants: A New Look at Infant Mortality, 1983 through 1985," Journal of the American Medical Association, CCLXII (1992), pp. 259-263.

Holman, Robert C., Umesh D. Parashar, Matthew J. Clarke, Stephen F. Kaufman, and Roger I. Glass, "Trends in Diarrhea-associated Hospitalizations Among American Indian and Alaska Native Children, 1980-1995," Pediatrics, CIII (1999). 
House of Representatives Subcommittee on Health and Safety of the Committee on Interstate and Foreign Commerce, "Indian Sanitation Facilities," published hearings May $5-6,1959$.

Kolluri, Lopa, and Kristopher M. Rengert, "Housing and Homeownership on American Indian Tribal Lands: Barriers, Progress, and the Promise of New Initiatives," Fannie Mae Foundation Housing Facts and Findings, II (2000).

MacDorman, Marian F. and Harry M. Rosenberg, "Trends in Infant Mortality by Cause of Death and Other Characteristics, 1960-88," National Center for Health Statistics, Vital Health Statistics Series 20 Number 20 (1993).

Miguel, Edward, and Michael Kremer, "Worms: Identifying Impacts on Education and Health in the Presence of Treatment Externalities," Econometrica, 72 (1), 2004.

Reyes, Jessica, "Environmental Policy as Social policy? The Impact of Childhood Lead Exposure on Crime," (http://www.eco.utexas.edu/facstaff/Reyes/), 2002.

Rhoades, Everett R, Anthony J. D’Angelo, and Ward B. Hurlbut, “The Indian Health Service Record of Achievement,” Public Health Reports, CII (1987), pp. 356-360.

Rhoades, E.R., G. Brenneman, J. Lyle, and A. Handler, "Mortality of American Indian and Alaska Native Infants," Annual Review of Public Health, XIII (1992), pp. 269-285.

Rubenstein, A., J. Boyle, C.L. Odoroff, and S.J. Kunitz, "Effect of Improved Sanitary Facilities on Infant Diarrhea in a Hopi Village," Public Health Reports, LXXXIV (1969), pp. 1093-1097.

Troesken, Werner, "Race, Disease, and the Provision of Water in American Cities, 18891921," The Journal of Economic History, LXI (2001), pp. 750-756.

UNICEF, Official Summary: The State of the World's Children 2002, (http://www.unicef.org/sowc02summary/table1.html), 2002.

U.S. Census Bureau, "Poverty in the United States: 2000," Current Population Reports: Consumer Income, 2001a.

U.S. Census Bureau, "Statistical Abstract of the United States: 2001," The National Data Book, 2001b.

U.S. Department of Health, Education and Welfare, "Relationship of Environmental Factors to Enteric Disease,” Public Health Monograph No. 54, 1958.

U.S. Public Health Service, Health Care Facilities Engineering Millenium Report, Office of Public Health, 2000. 
Viscusi, W.Kip, “The Value of Risks to Life and Health," Journal of Economic Literature, XXXI (1993), pp. 1912-1946.

World Health Organization, Water and Sanitation, (http://www.who.int/water_sanitation_health/), 2001.

World Bank, Data and Statistics, (http://www.worldbank.org/data/), 2002. 
Figure 1.

Infant Mortality by Race in Sample Areas, 1960-1998

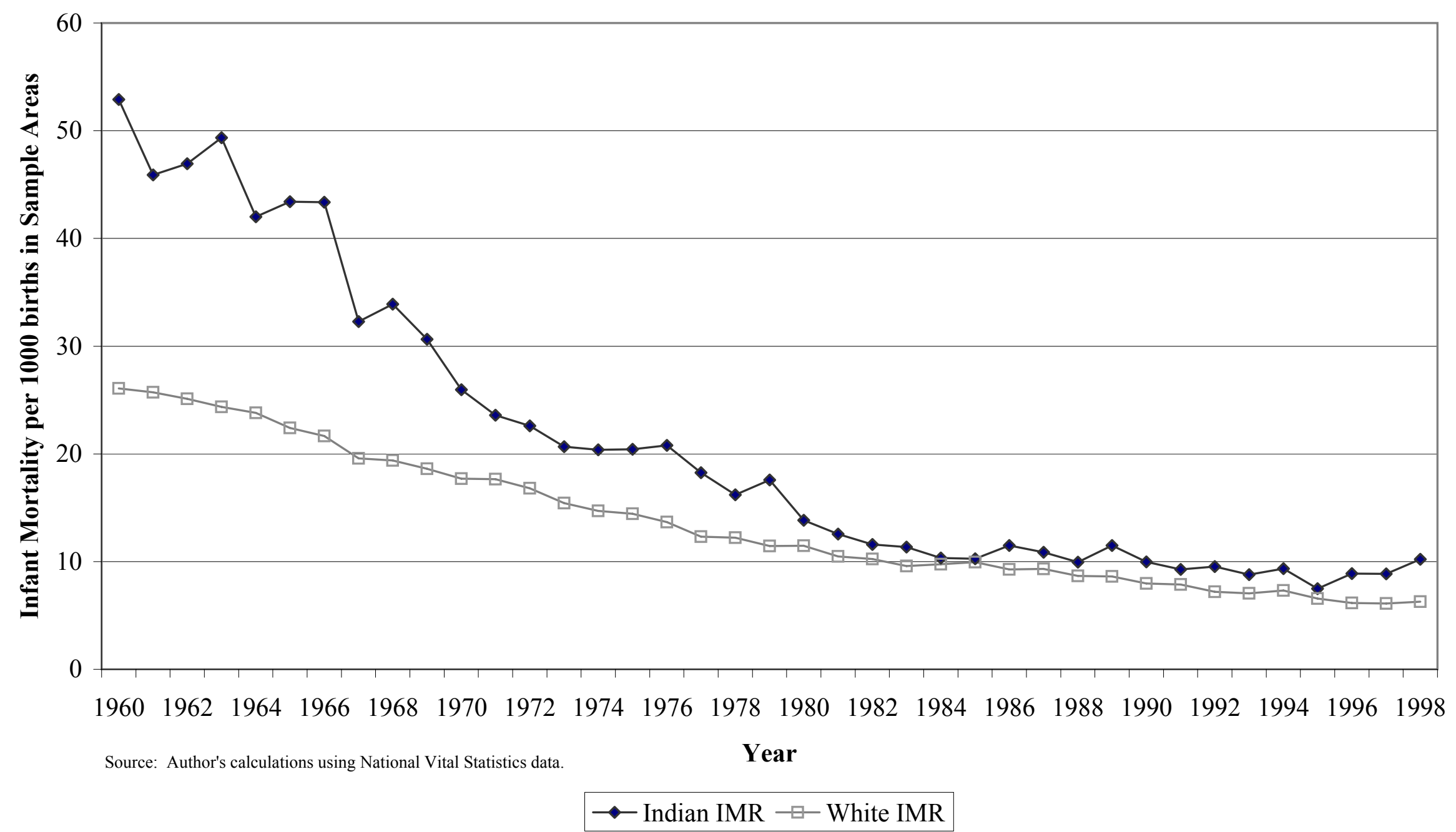


Table 1. Summary Statistics

Sample Description

$\begin{array}{lr}\text { Number of County Groups } & 38\end{array}$

$\begin{array}{lr}\text { Number of Years } & 39\end{array}$

Number of Observations $\quad 1,480$

$\begin{array}{ll}\text { Number of Counties Represented } & 224\end{array}$

$\begin{array}{lr}\text { Number of Projects Appropriated and Completed by } 2001 & 3,700\end{array}$

Total Number Indian Births $\quad 740,470$

$\begin{array}{lc}\text { Total Number Indian Infant Deaths } & 13,600\end{array}$

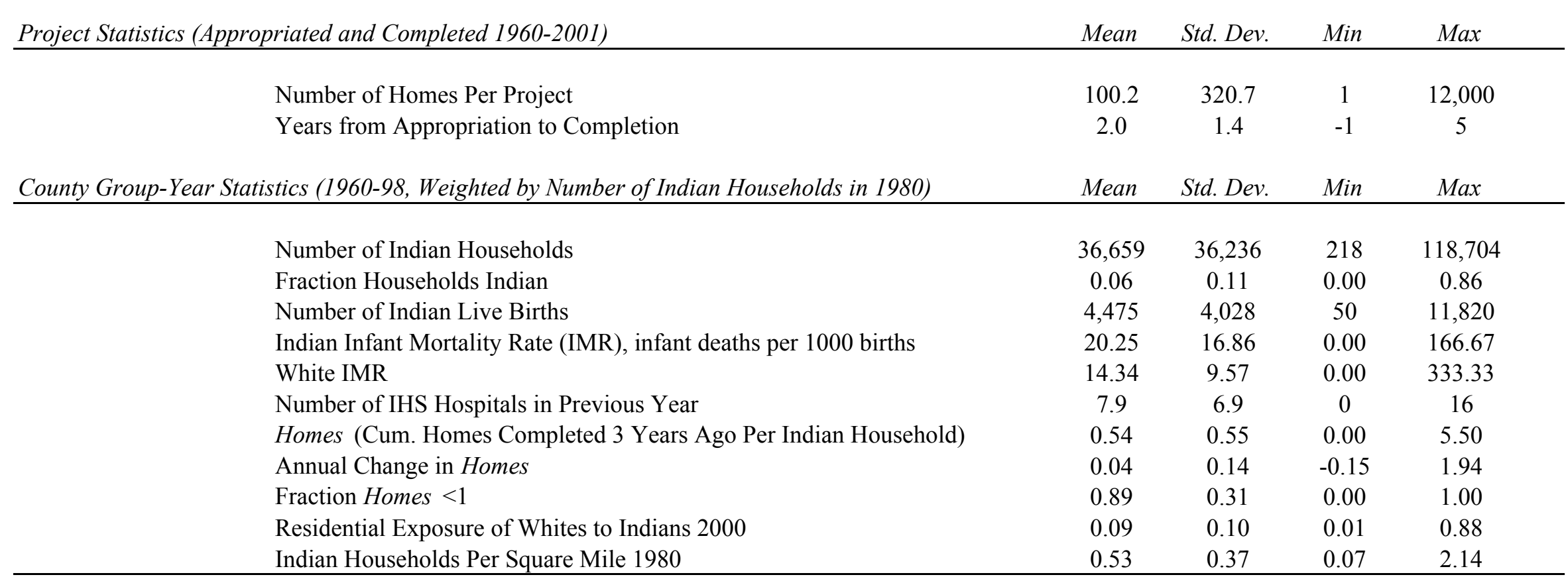


Figure 2. Trends in Cumulative Appropriation

(10 Largest County Groups By Native American Households in 1980)

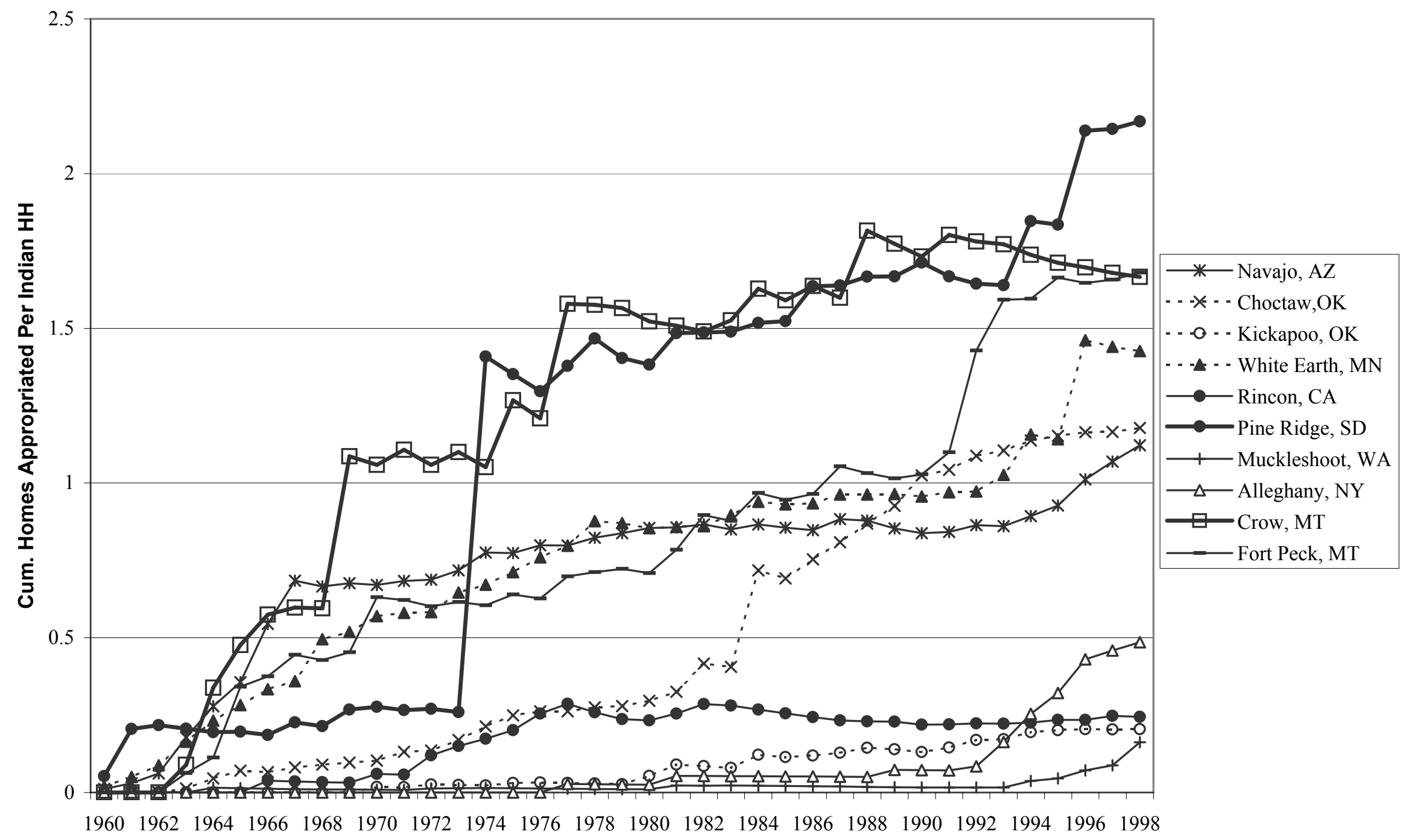


Figure 3a.

Effect of Cumulative Homes Affected Relative to Appropriation Date (coefficients and $95 \%$ confidence intervals from separate regressions)

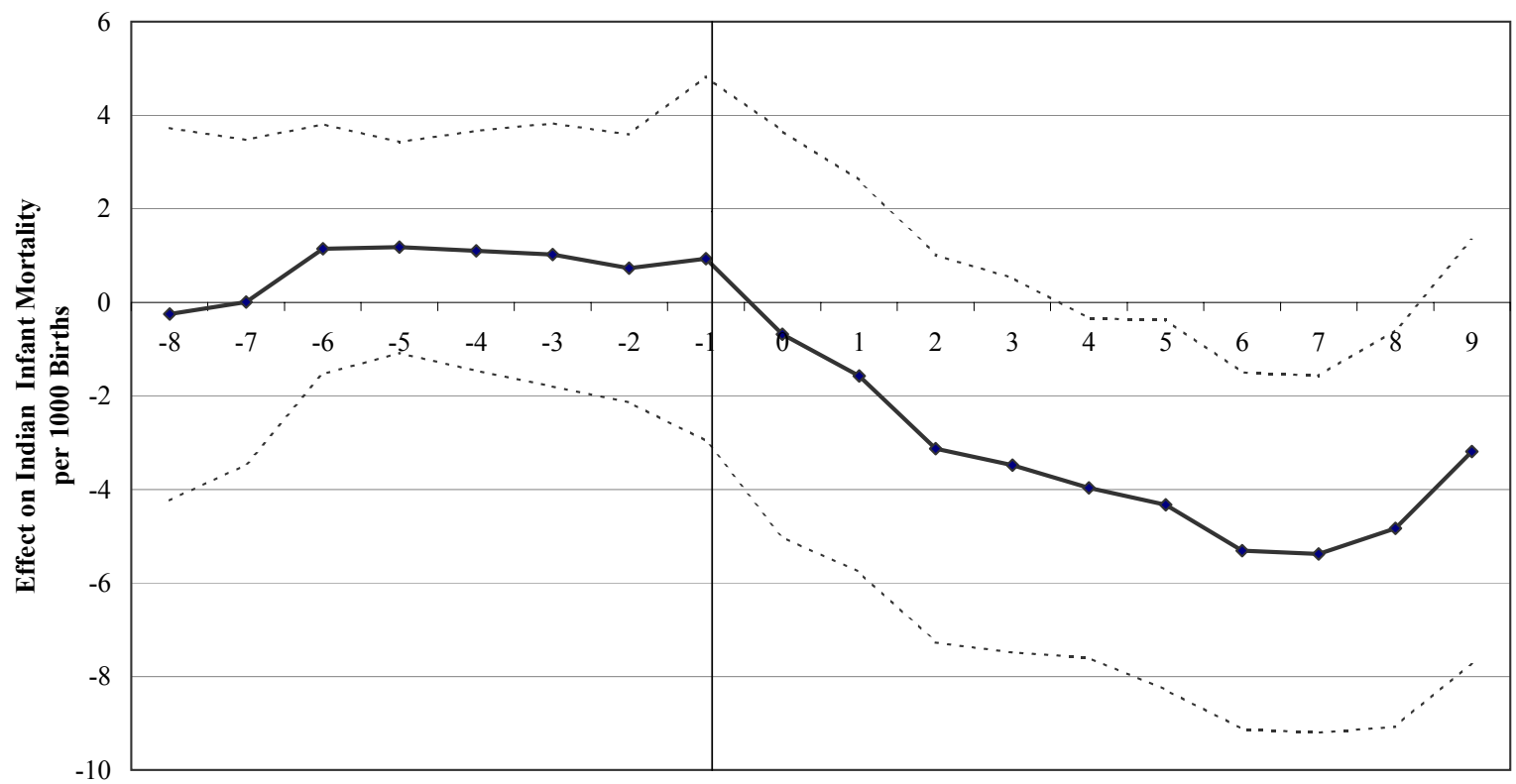

Years Since Appropriation

Figure 3b.

Effect of Cumulative Homes Affected Relative to Completion Date (coefficients and $95 \%$ confidence intervals from separate regressions)

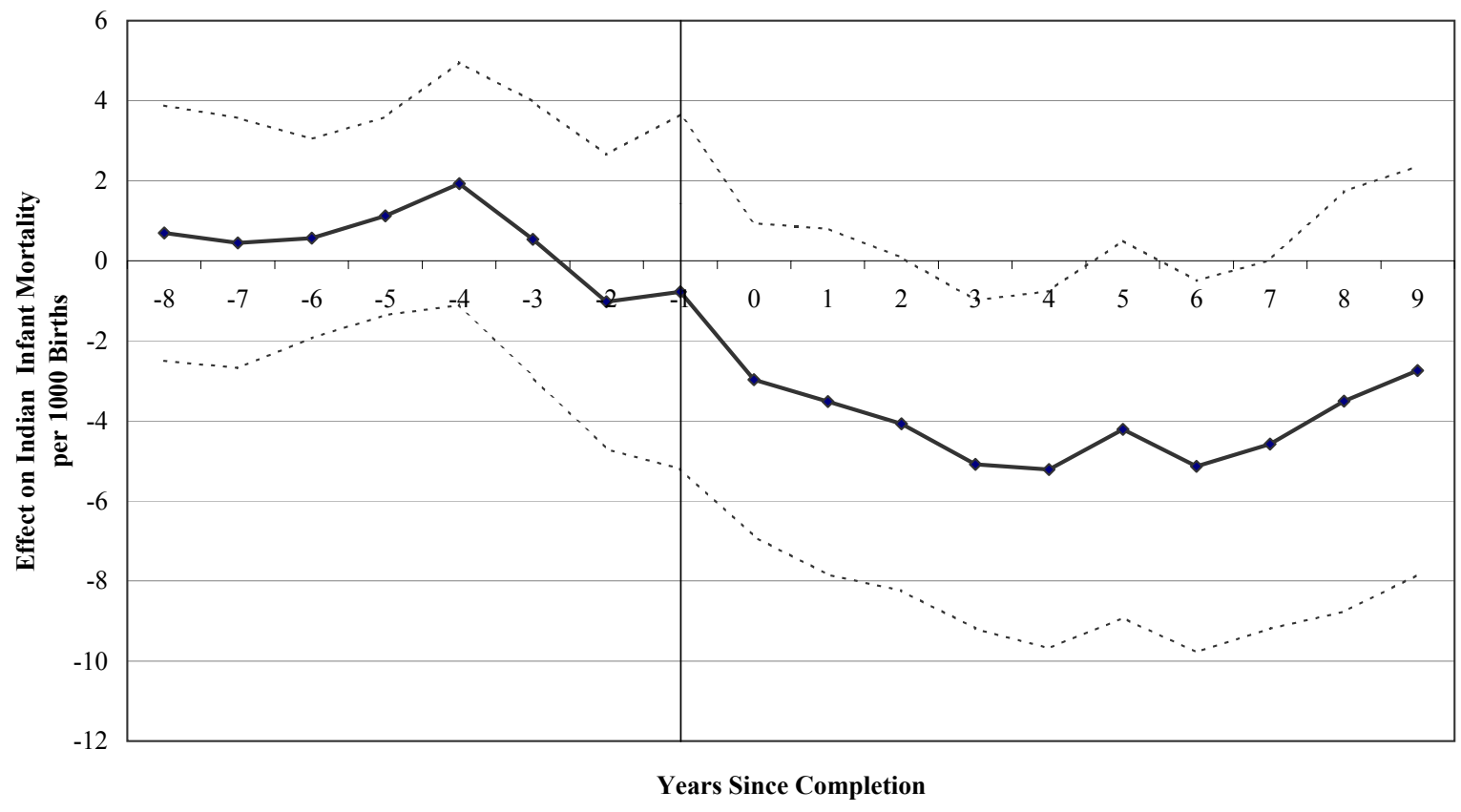




\section{Table 2. Effect of Projects on Indian Infant Mortality (coefficients from separate regressions)}

\begin{tabular}{|c|c|c|}
\hline $\begin{array}{c}\text { Dependent Variable: } \\
\text { Indian Infant Mortality Rate } \\
(\text { Mean=20.2, Initial Value }=45.6)\end{array}$ & $\begin{array}{c}\text { I } \\
\text { Effect of Treatment } \\
\text { Alternative Evaluation Years } \\
\text { Rel. to Completion Date }\end{array}$ & $\begin{array}{c}\text { II } \\
\text { Effect of Treatment } \\
\text { Alternative Evaluation Years } \\
\text { Rel. to Appropriation Date }\end{array}$ \\
\hline 5 year lead $(k=-5)$ & $\begin{array}{c}\mathbf{1 . 1 2} \\
(1.22)\end{array}$ & $\begin{array}{c}\mathbf{1 . 1 8} \\
(1.12)\end{array}$ \\
\hline 4 year lead $(k=-4)$ & $\begin{array}{c}\mathbf{1 . 9 3} \\
(1.50)\end{array}$ & $\begin{array}{c}\mathbf{1 . 1 0} \\
(1.27)\end{array}$ \\
\hline 3 year lead $(k=-3)$ & $\begin{array}{c}\mathbf{0 . 5 3} \\
(1.70)\end{array}$ & $\begin{array}{c}\mathbf{1 . 0 2} \\
(1.39)\end{array}$ \\
\hline 2 year lead $(k=-2)$ & $\begin{array}{l}\mathbf{- 1 . 0 2} \\
(1.81)\end{array}$ & $\begin{array}{c}\mathbf{0 . 7 3} \\
(1.41)\end{array}$ \\
\hline 2 year lead $(k=-1)$ & $\begin{array}{l}\mathbf{- 0 . 7 7} \\
(2.18)\end{array}$ & $\begin{array}{c}\mathbf{0 . 9 3} \\
(1.92)\end{array}$ \\
\hline Current Year & $\begin{array}{l}\mathbf{- 2 . 9 7} \\
(1.93)\end{array}$ & $\begin{array}{c}\mathbf{- 0 . 6 8} \\
(2.14)\end{array}$ \\
\hline 1 year lag $(k=1)$ & $\begin{array}{l}\mathbf{- 3 . 5 2} \\
(2.13)\end{array}$ & $\begin{array}{l}-\mathbf{1 . 5 8} \\
(2.07)\end{array}$ \\
\hline 2 year lag $(k=2)$ & $\begin{array}{l}-\mathbf{4 . 0 7 *} \\
(2.05)\end{array}$ & $\begin{array}{l}\mathbf{- 3 . 1 3} \\
(2.05)\end{array}$ \\
\hline 3 year lag $(k=3)$ & $\begin{array}{c}\mathbf{- 5 . 0 9 * *} \\
(2.03)\end{array}$ & $\begin{array}{l}-\mathbf{3 . 4 8 *} \\
(1.98)\end{array}$ \\
\hline 4 year lag $(k=4)$ & $\begin{array}{c}-\mathbf{5 . 2 2} * * \\
(2.20)\end{array}$ & $\begin{array}{c}\mathbf{- 3 . 9 7 * *} \\
(1.79)\end{array}$ \\
\hline 5 year lag $(k=5)$ & $\begin{array}{l}-\mathbf{4 . 2 1 *} \\
(2.33)\end{array}$ & $\begin{array}{c}-4.33 * * \\
(1.95)\end{array}$ \\
\hline 6 year lag $(k=6)$ & $\begin{array}{c}\mathbf{- 5 . 1 4 * *} \\
(2.29)\end{array}$ & $\begin{array}{c}\mathbf{- 5 . 3 1 * *} \\
(1.88)\end{array}$ \\
\hline 7 year lag $(k=7)$ & $\begin{array}{l}-4.58^{*} \\
(2.27)\end{array}$ & $\begin{array}{c}-\mathbf{- 5 . 3 8}^{* *} \\
(1.88)\end{array}$ \\
\hline 8 year lag $(k=8)$ & $\begin{array}{c}\mathbf{- 3 . 5 1} \\
(2.59)\end{array}$ & $\begin{array}{c}-4.84 * * \\
(2.09)\end{array}$ \\
\hline Number of Hospitals Last Year & yes & yes \\
\hline Log (Indian Households) & yes & yes \\
\hline County Group Dummies & yes & yes \\
\hline Year Dummies & yes & yes \\
\hline County Group-Specific Linear Time Trend & yes & yes \\
\hline $\begin{array}{l}\text { Number of Observations } \\
\text { Number of County Groups } \\
\text { Number of Years }\end{array}$ & $\begin{array}{l}\text { various } \\
38 \\
\text { various }\end{array}$ & $\begin{array}{l}\text { various } \\
38 \\
\text { various }\end{array}$ \\
\hline
\end{tabular}

Notes: Each cell represents a coefficient from a separate regression. Regressions, means, and initial values are weighted by estimated number of Indian households. Initial values based on 1960-1962 average. Standard errors are in parentheses and clustered by county group. ** and * indicate statistical significance at the 5 and 10 percent levels, respectively. Analysis is for years 1960-1998. Treatment defined as cumulative number of homes treated by year t-k per Indian household. One county group omitted for 1960 and 1961 because data is unavailable for Menominee County, WI. See data appendix for description of construction of county groups and variables. 
Table 3. Effect of Sanitation Projects on Indian Infant Mortality By Age of Infant

\begin{tabular}{|c|c|c|c|}
\hline Dependent Variable: & $\begin{array}{c}\text { Indian IMR } \\
(\text { Mean }=20.2, \\
\text { Initial Value }=45.6)\end{array}$ & $\begin{array}{c}\text { Neonatal } \\
\text { Indian IMR } \\
\text { (less than } 28 \text { days) } \\
\text { (Mean }=9.2, \\
\text { Initial Value }=18.3 \text { ) }\end{array}$ & $\begin{array}{c}\text { Post-neonatal } \\
\text { Indian IMR } \\
\text { (28 days to } 11 \text { months) } \\
\text { (Mean }=11.0, \\
\text { Initial Value }=27.3)\end{array}$ \\
\hline Homes (Cum. Homes Completed 3 Years Ago Per Indian HH) & $\begin{array}{c}-\mathbf{5 . 0 9} * * \\
(2.03)\end{array}$ & $\begin{array}{l}\mathbf{- 0 . 2 5} \\
(0.99)\end{array}$ & $-4.83 * *$ \\
\hline Number of Hospitals Previous Year & $\begin{array}{c}-1.27 * * \\
(0.38)\end{array}$ & $\begin{array}{l}\mathbf{- 0 . 1 1} \\
(0.28)\end{array}$ & $\begin{array}{c}\mathbf{- 1 . 1 6 * *} \\
(0.25)\end{array}$ \\
\hline Log (Indian Households) & yes & yes & yes \\
\hline County Group Dummies & yes & yes & yes \\
\hline Year Dummies & yes & yes & yes \\
\hline County Group-Specific Linear Time Trend & yes & yes & yes \\
\hline Number of Observations & 1480 & 1480 & 1480 \\
\hline Number of County Groups & 38 & 38 & 38 \\
\hline Number of Years & 39 & 39 & 39 \\
\hline R-squared & 0.79 & 0.57 & 0.74 \\
\hline
\end{tabular}

Notes: Regressions, means, and initial values are weighted by estimated number of Indian households. Initial values based on 1960-1962 average. Standard errors are in parentheses and clustered by county group. ** and * indicate statistical significance at the 5 and 10 percent levels, respectively. Analysis is for years 1960-1998. One county group omitted for 1960 and 1961 because data is unavailable for Menominee County, WI. See data appendix for description of construction of county groups and variables. 
Table 4. Effect of Sanitation Projects on Indian Infant Mortality By Disease (coefficients from separate regressions)

\begin{tabular}{|c|c|c|}
\hline \multicolumn{2}{|c|}{ Dependent Variable: Indian Infant Mortality Rate from Disease Cateoory } & $\begin{array}{c}\text { Coefficient on } \\
\text { Homes }(k=3)\end{array}$ \\
\hline Disease Categories Related to Sanitation & $($ mean $=4.61$, initial value $=16.16)$ & $\begin{array}{c}\mathbf{- 3 . 8 0}^{* * *} \\
(1.04)\end{array}$ \\
\hline Gastrointestinal Disease & (mean $=1.79$, initial value $=6.83)$ & $\begin{array}{l}-1.30 * \\
(0.64)\end{array}$ \\
\hline Certain GI Diseases (MR) & $($ mean $=1.32$, initial value $=2.50)$ & $\begin{array}{l}-\mathbf{1 . 3 0} * \\
(0.70)\end{array}$ \\
\hline Infectious Respiratory & $($ mean $=2.81$, initial value $=9.33)$ & $\begin{array}{c}-\mathbf{2 . 5 0 * *} \\
(0.85)\end{array}$ \\
\hline Pneumonia and Influenza (MR) & (mean $=1.95$, initial value $=2.74)$ & $\begin{array}{c}\mathbf{- 1 . 9 1 * *} \\
(0.59) \\
\end{array}$ \\
\hline Disease Categories Unrelated to Sanitation & (mean $=7.84$, initial value $=9.06)$ & $\begin{array}{c}\mathbf{- 0 . 4 1} \\
(1.20)\end{array}$ \\
\hline Congenital Anomalies (MR) & (mean $=2.50$, initial value $=3.82)$ & $\begin{array}{c}\mathbf{0 . 7 3} \\
(0.47)\end{array}$ \\
\hline SIDS (MR) & $($ mean $=0.30$, initial value $=0.00)$ & $\begin{array}{c}\mathbf{0 . 1 3} \\
(0.21)\end{array}$ \\
\hline Respiratory Distress Syndrome (MR) & $($ mean $=1.02$, initial value $=0.44)$ & $\begin{array}{l}-\mathbf{- 0 . 8 0 * *} \\
(0.39)\end{array}$ \\
\hline Short Gestation/Low Birthweight (MR) & (mean $=0.83$, initial value $=1.32)$ & $\begin{array}{c}\mathbf{0 . 2 7} \\
(0.19)\end{array}$ \\
\hline Maternal Complications of Pregnancy (MR) & (mean $=0.63$, initial value $=0.44)$ & $\begin{array}{l}\mathbf{- 0 . 5 4} \\
(0.41)\end{array}$ \\
\hline Intrauterine Hypoxia/Birth Asphyxia (MR) & $($ mean $=0.84$, initial value $=1.37)$ & $\begin{array}{c}\mathbf{0 . 2 8} \\
(0.39)\end{array}$ \\
\hline Perinatal Infections (MR) & (mean $=0.24$, initial value $=0.15)$ & $\begin{array}{c}\mathbf{0 . 0 7} \\
(0.17)\end{array}$ \\
\hline Accidents (MR) & $($ mean $=0.63$, initial value $=0.71)$ & $\begin{array}{l}-\mathbf{- 0 . 5 6 * *} \\
(0.17)\end{array}$ \\
\hline Complications of Placenta etc. (MR) & (mean $=0.26$, initial value $=0.21)$ & $\begin{array}{l}\mathbf{- 0 . 1 9} \\
(0.15)\end{array}$ \\
\hline Birth Trauma (MR) & (mean $=0.41$, initial value $=0.43)$ & $\begin{array}{c}\mathbf{0 . 1 1} \\
(0.20)\end{array}$ \\
\hline Hemolytic Disease of Newborn (MR) & $($ mean $=0.03$, initial value $=0.10)$ & $\begin{array}{l}\mathbf{- 0 . 0 7} \\
(0.05)\end{array}$ \\
\hline Diseases of Heart (MR) & $($ mean $=0.15$, initial value $=0.08)$ & $\begin{array}{c}\mathbf{0 . 1 7} \\
(0.10)\end{array}$ \\
\hline Number of Observations per Regression & & 1480 \\
\hline Number of County Groups per Regression & & 38 \\
\hline Number of Years per Regression & & 39 \\
\hline
\end{tabular}

Notes: Each cell represents a coefficient on the Homes variable from a separate regression. Disease categories related to sanitation are the sum of gastrointestinal and infectious respiratory. Disease categories unrelated to sanitation are all MR categories except certain GI and Pneumonia and Influenza. Regressions, means, and initial values are weighted by estimated number of Indian households. Initial values based on 1960-1962 average. Standard errors are in parentheses and clustered by county group. ${ }^{* *}$ and * indicate statistical significance at the 5 and 10 percent levels, respectively. Analysis is for years $1960-$ 1998. One county group omitted for 1960 and 1961 because data is unavailable for Menominee County, WI. See data appendix for description of construction of county groups and variables. 


\section{Table 5. Heterogeneous Treatment Effects}

\begin{tabular}{|c|c|c|c|}
\hline $\begin{array}{l}\text { Dependent Variable: Indian Infant Mortality Rate } \\
\text { (Mean=20.2, Initial Value 45.6) }\end{array}$ & $\mathrm{I}$ & $\begin{array}{c}\text { By Previous } \\
\text { Treatment Level } \\
\text { II } \\
\end{array}$ & $\begin{array}{c}\text { By Year } \\
\text { III }\end{array}$ \\
\hline Homes & $\begin{array}{l}\mathbf{- 5 . 0 9 * *} \\
(2.03)\end{array}$ & & \\
\hline Homes $*$ Dummy if Homes $<1$ & & $\begin{array}{c}-\mathbf{1 0 . 0 0 * *} \\
(2.33)\end{array}$ & \\
\hline Homes $*$ Dummy if Homes $>=1$ & & $\begin{array}{l}\mathbf{- 2 . 7 5} \\
(1.66)\end{array}$ & \\
\hline Homes $*$ Dummy if Year $<1973$ & & & $\begin{array}{c}-7.31 * * \\
(3.17)\end{array}$ \\
\hline Homes $*$ Dummy if Year $>=1973$ and $<1986$ & & & $\begin{array}{c}-\mathbf{5 . 1 6 * *} \\
(1.69)\end{array}$ \\
\hline Homes $*$ Dummy if Year $>1986$ & & & $\begin{array}{c}-4.54 * * \\
(1.69)\end{array}$ \\
\hline Dummies for Homes $>=1$ & & yes & \\
\hline Number of Hospitals Previous Year and Interactions & yes & yes & yes \\
\hline Log (Indian Households) & yes & yes & yes \\
\hline County Group Dummies & yes & yes & yes \\
\hline Year Dummies & yes & yes & yes \\
\hline County Group-Specific Linear Time Trend & yes & yes & yes \\
\hline Number of Observations & 1480 & 1480 & 1480 \\
\hline Number of County Groups & 38 & 38 & 38 \\
\hline Number of Years & 39 & 39 & 39 \\
\hline R-squared & 0.79 & 0.79 & 0.79 \\
\hline
\end{tabular}

Notes: Regressions, means, and initial values are weighted by estimated number of Indian households. Initial values based on 1960-1962 average. Standard errors are in parentheses and clustered by county group. $* *$ and $*$ indicate statistical significance at the 5 and 10 percent levels, respectively. Analysis is for years 1960-1998. One county group omitted for 1960 and 1961 because data is unavailable for Menominee County, WI. See data appendix for description of construction of county groups and variables. 
Table 6. Effect of Sanitation Projects on White Infant Mortality By Exposure to Native Americans

\begin{tabular}{|c|c|c|c|c|c|c|c|c|}
\hline Dependent Variable: & \multicolumn{4}{|c|}{$\begin{array}{c}\text { Infectious Respiratory White IMR } \\
(\text { Mean }=0.88, \text { Initial Value 2.95) }\end{array}$} & \multicolumn{4}{|c|}{$\begin{array}{l}\text { Gastrontestinal White IMR } \\
(\text { Mean }=0.18, \text { Initial Value }=0.51)\end{array}$} \\
\hline Homes & $\begin{array}{l}\mathbf{- 0 . 4 9 *} \\
(0.25)\end{array}$ & $\begin{array}{l}\mathbf{- 0 . 0 0} \\
(0.29)\end{array}$ & $\begin{array}{c}\mathbf{0 . 3 5} \\
(0.26)\end{array}$ & $\begin{array}{l}\mathbf{0 . 4 3 *} \\
(0.24)\end{array}$ & $\begin{array}{l}\mathbf{- 0 . 1 4} \\
(0.09)\end{array}$ & $\begin{array}{c}-\mathbf{0 . 3 9} * * \\
(0.16)\end{array}$ & $\begin{array}{c}\mathbf{- 0 . 3 8} * * \\
(0.16)\end{array}$ & $\begin{array}{c}\mathbf{- 0 . 4 5 * *} \\
(0.17)\end{array}$ \\
\hline Homes * Exposure of Whites to Indians 2000 & & $\begin{array}{l}-7.70 * \\
(4.37)\end{array}$ & & $\begin{array}{l}-4.01 \\
(4.36)\end{array}$ & & $\begin{array}{l}4.56 * * \\
(1.41)\end{array}$ & & $\begin{array}{l}4.27 * * \\
(1.39)\end{array}$ \\
\hline Homes * Density of Indian Households 1980 & & & $\begin{array}{l}-2.13 * * \\
(0.71)\end{array}$ & $\begin{array}{l}-1.71 * \\
(0.91)\end{array}$ & & & $\begin{array}{l}\mathbf{0 . 6 7 *} \\
(0.34)\end{array}$ & $\begin{array}{c}\mathbf{0 . 2 0} \\
(0.24)\end{array}$ \\
\hline Number of Hospitals Previous Year and Interactions & yes & yes & yes & yes & yes & yes & yes & yes \\
\hline Log (Indian Households) & yes & yes & yes & yes & yes & yes & yes & yes \\
\hline Log (White Households) & yes & yes & yes & yes & yes & yes & yes & yes \\
\hline County Group Dummies & yes & yes & yes & yes & yes & yes & yes & yes \\
\hline Year Dummies & yes & yes & yes & yes & yes & yes & yes & yes \\
\hline County Group-Specific Linear Time Trend & yes & yes & yes & yes & yes & yes & yes & yes \\
\hline Number of Observations & 1365 & 1365 & 1365 & 1365 & 1365 & 1365 & 1365 & 1365 \\
\hline Number of County Groups & 35 & 35 & 35 & 35 & 35 & 35 & 35 & 35 \\
\hline Number of Years & 39 & 39 & 39 & 39 & 39 & 39 & 39 & 39 \\
\hline R-squared & 0.86 & 0.86 & 0.86 & 0.86 & 0.54 & 0.55 & 0.55 & 0.56 \\
\hline
\end{tabular}

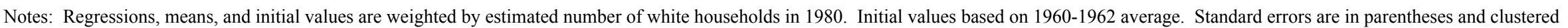
by county group. ** and * indicate statistical significance at the 5 and 10 percent levels, respectively. Analysis is for years 1960-1998 and weighted by number of white households in 1980 . All county groups with at least 50 Indian live births and 50 white live births in every year included except Alaska. See data appendix for description of construction of county groups and variables. 